\title{
Remote sensing of soot carbon - Part 2: Understanding the absorption Ångström exponent
}

\author{
G. L. Schuster ${ }^{1}$, O. Dubovik ${ }^{2}$, A. Arola ${ }^{3}$, T. F. Eck ${ }^{4,5}$, and B. N. Holben ${ }^{5}$ \\ ${ }^{1}$ NASA Langley Research Center, Hampton, VA, USA \\ ${ }^{2}$ Laboratoire d'Optique Atmosphérique, Université de Lillé 1, CNRS, Villeneuve d'Ascq, France \\ ${ }^{3}$ Finnish Meteorological Institute, P.O. Box 1627, 70211 Kuopio, Finland \\ ${ }^{4}$ Universities Space Research Association, Columbia, MD, USA \\ ${ }^{5}$ NASA Goddard Space Flight Center, Greenbelt, MD, USA \\ Correspondence to: G. L. Schuster (gregory.1.schuster@nasa.gov)
}

Received: 24 March 2015 - Published in Atmos. Chem. Phys. Discuss.: 5 August 2015

Revised: 17 November 2015 - Accepted: 25 November 2015 - Published: 11 February 2016

\begin{abstract}
Recently, some authors have suggested that the absorption Ångström exponent (AAE) can be used to deduce the component aerosol absorption optical depths (AAODs) of carbonaceous aerosols in the AERONET database. This $\mathrm{AAE}$ approach presumes that $\mathrm{AAE} \ll 1$ for soot carbon, which contrasts the traditional small particle limit of AAE = 1 for soot carbon. Thus, we provide an overview of the AERONET retrieval, and we investigate how the microphysics of carbonaceous aerosols can be interpreted in the AERONET AAE product. We find that $\mathrm{AAE} \ll 1$ in the AERONET database requires large coarse mode fractions and/or imaginary refractive indices that increase with wavelength. Neither of these characteristics are consistent with the current definition of soot carbon, so we explore other possibilities for the cause of AAE $\ll 1$. AAE is related to particle size, and coarse mode particles have a smaller AAE than fine mode particles for a given aerosol mixture of species. We also note that the mineral goethite has an imaginary refractive index that increases with wavelength, is very common in dust regions, and can easily contribute to $\mathrm{AAE} \ll 1$. We find that $\mathrm{AAE} \ll 1$ can not be caused by soot carbon, unless soot carbon has an imaginary refractive index that increases with wavelength throughout the visible and near-infrared spectrums. Finally, AAE is not a robust parameter for separating carbonaceous absorption from dust aerosol absorption in the AERONET database.
\end{abstract}

\section{Introduction}

The aerosol robotic network (AERONET) is composed of hundreds of sun-sky scanning radiometers located at surface sites throughout the world, which are robotically controlled, solar powered, and weather hardened so that they may operate autonomously (Holben et al., 1998). These narrow-fieldof-view instruments provide frequent aerosol optical depth measurements in the $0.340-1.02 \mu \mathrm{m}$ spectral range throughout the day. The radiometers also measure sky radiances at a wide range of scattering angles, and these data are incorporated into a radiometric retrieval algorithm to infer aerosol absorption (Dubovik and King, 2000). The absorption Ångström exponent and the absorption aerosol optical depth represent two of the aerosol absorption products available in the AERONET database at http://aeronet.gsfc.nasa. gov.

The absorption Ångström exponent (AAE) is defined by a power law relationship with the absorption aerosol optical depth (AAOD) or the aerosol absorption coefficient $\left(C_{\mathrm{abs}}\right)$ :

$$
\xi(\lambda)=\xi(1) \lambda^{-\mathrm{AAE}} \text {. }
$$

Here, $\xi$ is a generic variable for absorption that can represent either AAOD or $C_{\text {abs }}, \lambda$ represents wavelength, and $\xi(1)$ is the power law value for $\xi$ at a reference wavelength of $1 \mu \mathrm{m}$. If $\operatorname{AAOD}(\lambda)$ or $C_{\mathrm{abs}}(\lambda)$ are known at two or more wavelengths, then AAE can be obtained by linear regression of the logarithm of Eq. (1). (Note that some authors use a reference wavelength of $0.55 \mu \mathrm{m}$ instead of $1 \mu \mathrm{m}$, but this does not 
affect the derived value of AAE. Additionally, some authors have noted that AAE is not necessarily constant throughout the visible and near-infrared wavelengths at East Asian AERONET sites; Eck et al., 2010; Li et al., 2015). The spectral dependence of absorption (i.e., AAE) depends upon particle size and the imaginary refractive index, and excellent overviews of the relationship between AAE and aerosol microphysics are provided by Moosmüller et al. $(2009,2011)$.

Generally, AAE is obtained from photoacoustic measurements (Lewis et al., 2008; Chow et al., 2009; Gyawali et al., 2009; Flowers et al., 2010; Lack et al., 2012b; Chakrabarty et al., 2013; Utry et al., 2014), particle soot absorption photometer measurements (Roden et al., 2006), aethalometer measurements (Ganguly et al., 2005), the solar-flux-AOD technique (Russell et al., 2010), integrating plate methods (Schnaiter et al., 2003), differencing extinction and scattering coefficients (Schnaiter et al., 2006), or aerosol robotic network (AERONET) retrievals (Bahadur et al., 2012; Chung et al., 2012b; Giles et al., 2012; Cazorla et al., 2013; Xu et al., 2013; Russell et al., 2014).

The AAE parameter is appealing because $\mathrm{AAE}=1$ in the Rayleigh limit for small particles that have wavelengthindependent refractive indices throughout the visible and near-infrared wavelengths (Bohren and Huffman, 1983; Moosmüller et al., 2009, 2011). Since soot carbon (sC) has a spectrally invariant imaginary refractive index at visible wavelengths (Bond and Bergstrom, 2006; Bond et al., 2013) and primary spherule sizes are less than about $50 \mathrm{~nm}$ (Mulholland and Mountain, 1999; Pósfai et al., 2003), we expect $\mathrm{AAE}=1$ when externally mixed soot carbon is the only absorbing aerosol present (Bergstrom et al., 2002; Andreae, 2006; Bergstrom et al., 2007; Moosmüller et al., 2009). Other absorbing aerosols typically exhibit AAE $>1$, so aerosol scientists can use AAE to determine whether soot carbon is the dominant absorbing aerosol in their measurements (Bergstrom et al., 2002; Russell et al., 2010).

Recently, some authors have suggested that AAE can also be used to deduce the component AAODs of dust, brown carbon $(\mathrm{BrC})$, and soot carbon in the atmosphere (Bahadur et al., 2012; Chung et al., 2012b; Bond et al., 2013; Cazorla et al., 2013; Xu et al., 2013). The premise behind this AAE approach is that AAE is a species-dependent aerosol property that does not depend upon particle size or mass, that absorbing aerosol species are externally mixed with one another, and that $\mathrm{AAE} \ll 1$ for soot carbon. Other authors have found that AAE does not contain enough information to unambiguously speciate the absorbing aerosols (Bergstrom et al., 2007; Gyawali et al., 2009; Lack and Cappa, 2010; Giles et al., 2012; Lack and Langridge, 2013). Thus, we explore this topic here, and we point out some theoretical inconsistencies associated with using the AAE approach to deduce component AAODs from the AERONET retrievals.

We begin by defining our choice of nomenclature in Sect. 2, which has become an unfortunate necessity in this business. Then we illustrate how the imaginary refractive in- dex $(k(\lambda))$ is related to particle absorption, and we introduce the common absorbing atmospheric aerosols (Sect. 3). Next, we discuss how aerosol microphysical and optical properties affect the AAE, using a simple model that only considers spectrally invariant $k$ (Sects. 4 and 5). We also discuss how to interpret the AERONET retrievals in the context of this simple model (Sect. 6). Then we discuss the affect of spectrally variable $k(\lambda)$ on AAE (Sect. 7). Finally, we provide an overview of the AAE approach used by other authors and discuss its limitations in Sect. 8.

\section{Carbonaceous aerosol nomenclature}

Soot carbon is a byproduct of combustion that is composed of aggregated graphite spheres (Andreae and Gelencsér, 2006). It is often called light absorbing carbon (LAC), black carbon (BC), refractory black carbon ( $\mathrm{rBC}$ ), or elemental carbon $(\mathrm{EC})$ in the scientific literature (depending upon the measurement technique), but we prefer the carbonaceous aerosol definitions nicely presented by Andreae and Gelencsér (2006). Thus, the term $\mathrm{sC}$ presented here is equivalent to $\mathrm{LAC}$ in Bond and Bergstrom (2006) and BC or $\mathrm{rBC}$ in Bond et al. (2013). Loosely, the term EC refers to $\mathrm{sC}$ that is obtained by thermal techniques, and the term $\mathrm{BC}$ refers to $\mathrm{SC}$ that is obtained by optical techniques; the term $\mathrm{BC}$ is also used generically by the modeling community. We use the term $\mathrm{BrC}$ for absorbing organic matter to distinguish these particles from organic matter that does not absorb significantly at visible wavelengths (Jacobson, 1999; Kirchstetter et al., 2004; Kanakidou et al., 2005; Hoffer et al., 2006; Schnaiter et al., 2006; Sun et al., 2007; Dinar et al., 2008; Chen and Bond, 2010). However, both $\mathrm{BrC}$ and organic carbon are composed of many organic species, and the $\mathrm{BrC}$ detected in the atmosphere also contains some non-absorbing organic particulates as well (i.e., the scientific community has probably not isolated "pure" $\mathrm{BrC}$ ).

\section{Absorbing aerosols in the atmosphere}

The attenuation of radiation in homogenous bulk matter is defined by the exponential law of attenuation (Bohren and Clothiaux, 2006):

$F(\lambda)=F_{0}(\lambda) e^{-\alpha_{\text {bulk }}(\lambda) d}$,

where $F_{0}$ is the irradiance incident upon the material, $F$ is the irradiance at depth $d$, and $\alpha_{\text {bulk }}$ is the bulk absorption coefficient. The bulk absorption coefficient is directly related to the imaginary part of the complex refractive index for the absorbing medium $(k)$ :

$\alpha_{\text {bulk }}(\lambda)=\frac{4 \pi k(\lambda)}{\lambda}$.

Although Eq. (3) demonstrates the importance of $k(\lambda)$ in evaluating the intrinsic absorption of a material, it is not 


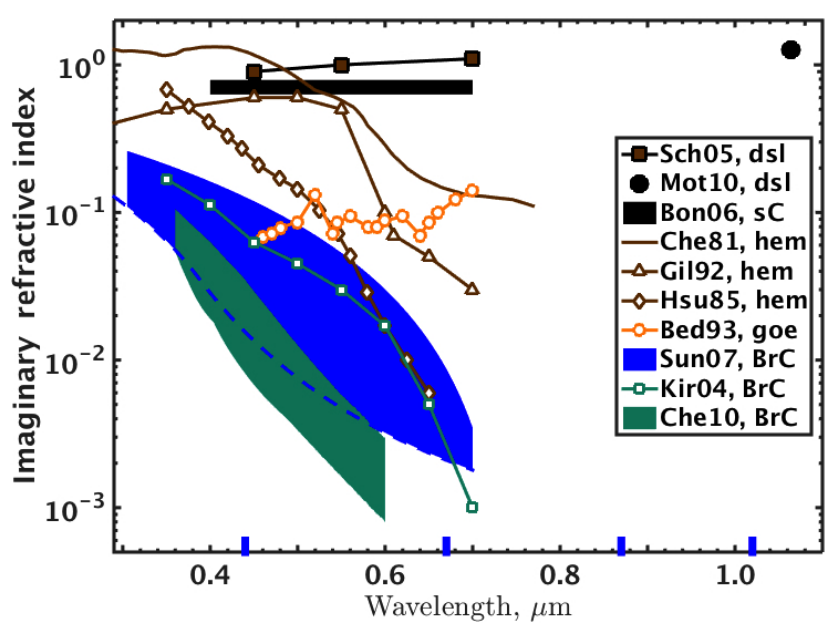

Figure 1. Imaginary refractive index of diesel (dsl), soot carbon (sC), hematite (hem), goethite (goe), and brown carbon (BrC), as measured or inferred by several sources. Thick blue ticks at bottom indicate the AERONET retrieval wavelengths. Legend code: Sch05 is Schnaiter et al. (2005); Mot10 is Moteki et al. (2010); Bnd06 is Bond and Bergstrom (2006); Che81 is Chen and Cahan (1981); Gil92 is Gillespie and Lindberg (1992); Bed93 isBedidi and Cervelle (1993); Sun07 is Sun et al. (2007); Kir04 is Kirchstetter et al. (2004); Che10 is Chen and Bond (2010).

suitable for determining the absorption coefficient of small particles (Sun et al., 2007; Moosmüller et al., 2011); this is because the exponential law does not account for the boundary conditions imposed upon the electric field by matter that is wholly encompassed in the field. Computation of small particle absorption coefficients requires the use of a particle model (such as Mie theory for spherical particles). We will not review the various small particle absorption and scattering models here, but particle absorption is intrinsically related to $k(\lambda)$.

We present $k(\lambda)$ for some common absorbing atmospheric aerosols in Fig. 1. Carbonaceous aerosols are composed of soot carbon and organic matter; some of the organic matter absorbs radiation at visible and ultraviolet wavelengths (Jacobson, 1999; Kanakidou et al., 2005), which we call brown carbon. Soot carbon is ubiquitous in the atmosphere, highly absorbing, and it has a spectrally invariant $k$ throughout the visible wavelengths (Bond and Bergstrom, 2006; Moteki et al., 2010). Brown carbon is highly absorbing at UV and blue wavelengths, and it has a strong spectral dependence of absorption that tapers off to unmeasurable values at nearinfrared wavelengths (Kirchstetter et al., 2004; Hoffer et al., 2006; Sun et al., 2007; Dinar et al., 2008; Chakrabarty et al., 2010; Chen and Bond, 2010; Lack et al., 2012a).

Iron oxide is responsible for light absorption in dust, and hematite and goethite are different phases of iron oxide that have significantly different spectral signatures (Linke et al., 2006). Hematite has a strong spectral dependence with a negative slope for $\mathrm{d} k / \mathrm{d} \lambda$ at most ultraviolet and visible wave- lengths (Chen and Cahan, 1981; Gillespie and Lindberg, 1992; Bedidi and Cervelle, 1993), and it is responsible for the reddish tint of some mineral mixtures. Goethite, however, has a positive overall slope for $\mathrm{d} k / \mathrm{d} \lambda$ at visible wavelengths, and it is responsible for the yellowish tint of some mineral mixtures. Both phases of iron oxide are radiatively important and similarly abundant in dust, as the goethite fraction of iron oxide in dust varies from 0.4 to more than 0.7 (Lafon et al., 2006; Shi et al., 2012; Formenti et al., 2014). Hematite and goethite range in size from a few nanometer to a micrometer (Shi et al., 2012). Many measurements of the hematite imaginary index exist in the literature (we show three of them in Fig. 1), but we have only found one such measurement for goethite (Bedidi and Cervelle, 1993). Given the prevalence and importance of goethite in aeolian dust, clearly there is a need for additional measurements of its refractive index.

Since hematite and $\mathrm{BrC}$ exhibit enhanced $k(\lambda)$ at $\mathrm{UV}$ and visible wavelengths (and therefore enhanced absorption at those wavelengths), these aerosols tend to produce larger AAE than similarly absorbing particles with spectrally invariant refractive indices (Russell et al., 2010; Moosmüller et al., 2011). Nonetheless, spectral variability of $k(\lambda)$ is not the only source of variability in AAE, and we first discuss the variability of AAE associated with mixing state and size of soot carbon.

\section{AAE for spectrally invariant $k$}

Figure 2 shows a contour plot of AAE as a function of imaginary refractive index and size for monomodal lognormal size distributions with a standard deviation of $\sigma=0.38$ and a real refractive index of $n=1.49$ (see Eq. 1 in Dubovik et al., 2002a), which are plausible values for fine mode carbonaceous aerosols. In order to define the contours, we used Mie theory to compute AAOD at $0.44,0.675$, and $0.87 \mu \mathrm{m}$, and we determined AAE by linear regression of the logarithm of Eq. (1) (e.g., Schuster et al., 2006). (We omitted the $1.020 \mu \mathrm{m}$ wavelength in our AAE computations in order to provide consistency with the AERONET AAE product discussed later.) The magenta ticks indicate typical fine and coarse mode geometric mean radii in the AERONET database (Dubovik et al., 2002a).

As discussed in Sect. 3, particle absorption is directly related to the imaginary refractive index, $k(\lambda)$. Soot carbon has a very high imaginary refractive index at visible wavelengths $\left(k_{\mathrm{SC}}(\lambda)=0.63\right.$ to 0.79 , per Bond and Bergstrom, 2006), and scattering aerosols that contain $\mathrm{sC}$ have effective imaginary refractive indices between 0 and $k_{\mathrm{SC}}(\lambda)$. Thus, we can use Fig. 2 to understand how the relative fraction of $\mathrm{sC}$ that is internally mixed with scattering aerosols affects the AAE.

First, we determine where externally mixed $\mathrm{sC}$ is located in the parameter space of Fig. 2. Soot carbon is composed of primary spherules with radii $R_{\mathrm{p}} \lesssim 0.025 \mu \mathrm{m}$ that are aggregated with other spherules into large particles, and the 


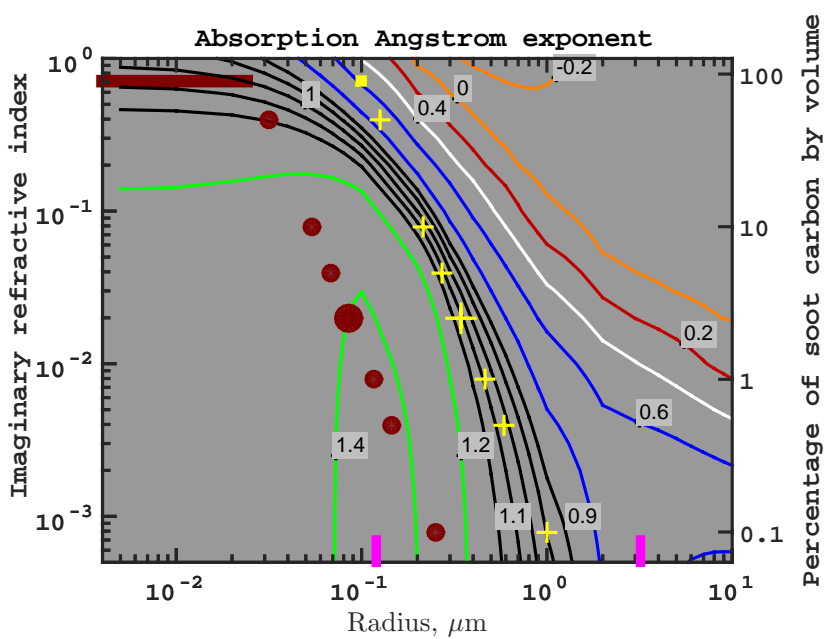

Figure 2. AAE (440-870) contours for lognormal particle size distributions with refractive index $n=1.49$ and mode width $\sigma=0.38$. Shaded maroon rectangle at the top of the plot indicates range of values for externally mixed $\mathrm{sC}$ using primary spherule sizes (radii $\lesssim 0.025 \mu \mathrm{m}$ ); the yellow square corresponds to externally mixed $\mathrm{sC}$ with a median radius of $0.1 \mu \mathrm{m}$. Symbols indicate internal mixing of $0.025 \mu \mathrm{m}$ (circles) or $0.10 \mu \mathrm{m}$ ("+") sC with scattering aerosols for $\mathrm{sC}$ volume fractions of $0.1,0.5,1,2.5,5,10$, and 50 percent. The black lines denote $\mathrm{AAE}=1 \pm 0.1$. Magenta ticks located at $R=0.12$ and $3.2 \mu \mathrm{m}$ are typical fine and coarse mode median radii in the AERONET database.

resulting agglomerates look like chains of spheres with multiple branches (hence the term "chain aggregates;" Li et al., 2003a, b; Wentzel et al., 2003; Chakrabarty et al., 2006; Adachi et al., 2010; Wu et al., 2012; Chakrabarty et al., 2013). The absorption cross section for the aggregated particles can be reasonably modeled as a collection of the primary $\mathrm{sC}$ spheres, even though the agglomerates have complex shapes (Mulholland et al., 1994; Fuller, 1995; Farias et al., 1996; Fuller et al., 1999; Sorensen, 2001; Schnaiter et al., 2003; Chakrabarty et al., 2007; Liu et al., 2008; Chung et al., 2012a). Thus, the primary spherule size is the appropriate length scale for determining AAE (Bergstrom et al., 2002), and externally mixed sC aggregates occupy the parameter space highlighted by the maroon rectangle in the upper left of Fig. 2. Note that AAE $=1 \pm 0.05$ for this region, which is consistent with the Rayleigh absorption limit for small particles (Bohren and Huffman, 1983; Bergstrom et al., 2002; Schnaiter et al., 2003; Moosmüller et al., 2009). This is also consistent with measurements (Rosen et al., 1978; Bergstrom et al., 2002; Schnaiter et al., 2003; Kirchstetter et al., 2004; Clarke et al., 2007) and therefore has become the de facto AAE for $\mathrm{sC}$ in the scientific literature (Sato et al., 2003; Bond and Bergstrom, 2006; Andreae and Gelencsér, 2006; Hoffer et al., 2006; Lewis et al., 2008; Moosmüller et al., 2009; Arola et al., 2011).

Soot carbon particles that are internally mixed with larger host aerosols result in particles with lower refractive indices and larger radii than the pure $\mathrm{sC}$ of the maroon shaded region in Fig. 2. This is shown by the seven maroon circles for $\mathrm{sC}$ particles in mixtures with $0.1,0.5,1,2.5,5,10$, and $50 \% \mathrm{sC}$ by volume. Note that internal mixing of $\mathrm{sC}$ has the interesting effect of increasing the AAE of the aerosol mixture to values of 1.4 and higher as the volume fraction of $\mathrm{sC}$ decreases, even though we used wavelength-independent $k$ values for our computations (see also Lack and Langridge, 2013). Also note that $\mathrm{AAE}<1$ is not possible in Fig. 2 for mixtures that contain $\mathrm{sC}$ particles sizes less than $0.025 \mu \mathrm{m}$ in radius.

Aggregated $\mathrm{sC}$ size distributions have equivalent sphere mass median radii of 0.085-0.135 $\mu \mathrm{m}$ (Martins et al., 1998; Mallet et al., 2003; Clarke et al., 2004; Moteki et al., 2007; Schwarz et al., 2008a, 2010; Kondo et al., 2011). The yellow square shows that $\mathrm{AAE} \simeq 0.6$ for externally mixed $\mathrm{sC}$ if we use a median radius of $0.1 \mu \mathrm{m}$ for our computations, as in Chung et al. (2012a). (Chung et al., 2012a, used a count mean diameter of $0.122 \mu \mathrm{m}$ and geometric standard deviation of 1.5, which corresponds to a volume median radius of $0.1 \mu \mathrm{m})$. However, the AAE increases to $\mathrm{AAE}=1 \pm 0.1$ when a $\mathrm{SC}$ core is internally mixed with a scattering aerosol in our case (yellow "+" symbols), whereas Chung et al. (2012a) found $\mathrm{AAE}<1$ for all particle sizes in their core-shell computations. We attribute the low AAEs computed by Chung et al. (2012a) to their assumption of a soot carbon refractive index that increases substantially with respect to wavelength (from $k_{\mathrm{SC}}=0.64$ at the $0.450 \mu \mathrm{m}$ wavelength to $k_{\mathrm{SC}}=0.78$ at the $0.700 \mu \mathrm{m}$ wavelength).

Note that we can not use the aggregated equivalent sphere $\mathrm{sC}$ particle sizes (i.e., yellow square and "+" symbols in Fig. 2) to model the absorption associated with the AERONET retrievals. This is because internal mixing of $0.1 \mu \mathrm{m}$ radius particles at $\mathrm{sC}$ concentrations low enough to produce the imaginary refractive indices found in the AERONET database produce unreasonably large size distributions. For instance, the four " + " symbols with $\leq 2.5 \% \mathrm{sC}$ in Fig. 2 require mode radii $\geq 0.34 \mu \mathrm{m}$, which is a factor of $\sim$ 3 larger than typically observed in the AERONET database (Dubovik et al., 2002a). That is not to say that the in situ measurements indicating median mode radii of $0.1 \mu \mathrm{m}$ for $\mathrm{sC}$ are incompatible with the AERONET retrievals. Rather, this inconsistency between in situ measurements and AERONET retrievals occurs because the in situ analyses are applied to particles that have been isolated from the other aerosols in the atmosphere, whereas the AERONET retrieval algorithm is applied to all particles in the atmosphere. This is discussed further in Sect. 6, where we review some of the fundamentals of the AERONET retrieval algorithm.

It is interesting to note the large parameter space in Fig. 2 where $\mathrm{AAE}>1$, even though we used identical refractive indices at three wavelengths to compute the isolines in this figure. Thus, hematite or $\mathrm{BrC}$ is not required in an aerosol mixture to observe $\mathrm{AAE}>1$, and $\mathrm{sC}$ that is internally mixed with purely scattering aerosols can easily produce AAEs of 1.4. Note that AERONET typically indicates $k=0.01-0.02$ 
Table 1. AERONET sites used in this study.

\begin{tabular}{l}
\hline Dust sites \\
\hline West Africa (waf): Agoufou, Banizoumbou, IER_Cinzana, \\
DMN_Maine_Soroa, Ouagadougou, Djougou, Saada, \\
Capo_Verde, Dahkla, Dakar, Ilorin, Quarzazate, \\
Santa_Cruz_Tenerife, Tamanrasset_INM, Tamanrasset_TMP. \\
\hline Middle East (mea): Solar_Village, Nes_Ziona, \\
SEDE_BOKER, Dhabi, Hamim. \\
\hline Biomass burning sites \\
\hline Southern Africa (saf): Mongu, Skukuza. \\
\hline South America (sam): Alta_Floresta, Cuiabá, \\
CUIABA-MIRANDA, Abracos_Hill, Balbina, Belterra, \\
SANTA_CRUZ.
\end{tabular}

in biomass burning regions (Dubovik et al., 2002a), which corresponds to $1-2.5 \% \mathrm{sC}$ and an AAE of $\sim 1.4$ in Fig. 2. This is also discussed in Lack and Langridge (2013).

Figure 2 also indicates that $\mathrm{AAE}<1$ is achieved for a large range of mode radii and $k$ values. Note that $\mathrm{AAE}<1$ is achieved with any imaginary refractive index, as long as the median mode radius is greater than $2 \mu \mathrm{m}$. (A typical coarse mode median radius in the AERONET database is $3.2 \mu \mathrm{m}$, as denoted by the rightmost magenta tick on abscissa in Fig. 2.) Very little aerosol absorption is required to achieve $\mathrm{AAE}<1$ for these large particles, as seen when $k=0.0005$ for $R_{\mathrm{m}} \geq 2 \mu \mathrm{m}$. (Note that $k=0.0005$ is the minimum $k$ value reportable by AERONET.) This can occur for coarse mode clay mixtures of illite, kaolinite, and montmorillonite that have spectrally invariant refractive indices. $\mathrm{AAE}<1$ can also occur at higher values of $k$ when $\mathrm{SC}$ is internally mixed with mineral clays in the coarse mode (Clarke et al., 2004; Yang et al., 2009; Hand et al., 2010) or in the absence of carbonaceous aerosols when goethite concentrations are suitably balanced with hematite concentrations (since $\mathrm{d} k / \mathrm{d} \lambda>1$ for goethite and $\mathrm{d} k / \mathrm{d} \lambda<1$ for hematite, per Fig. 1).

Finally, we recognize that the position of the contours in Fig. 2 are sensitive to the parameters that we used to compute the figure (i.e., the real refractive index and geometric standard deviation). However, we note that Bond (2001) and Gyawali et al. (2009) produced similar figures with similar qualitative results. In particular, Gyawali et al. (2009) used a core-shell model to compute AAE for mono-disperse soot with non-absorbing coatings, and they found that the carbon core diameter needed to be larger than $\sim 0.1 \mu \mathrm{m}$ in order to achieve AAE values less than 1. Additionally, carbon cores with $\mathrm{BrC}$ shells required even larger radii in order to achieve AAE $<1$ (see Gyawali et al., 2009, Fig. 8).

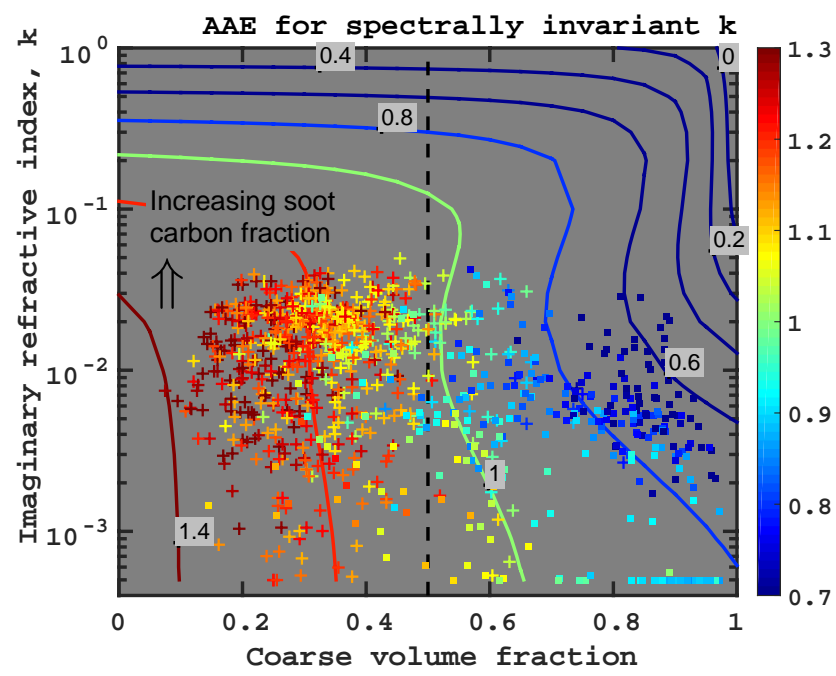

Figure 3. Contours represent AAE (440-870) for bimodal lognormal distributions with $n=1.49, R_{\text {fin }}=0.12 \mu \mathrm{m}, \sigma_{\text {fin }}=0.38$, $R_{\text {crs }}=3.2 \mu \mathrm{m}, \sigma_{\text {crs }}=0.75$. Data are AAE $(440-870)$ at all AERONET sites of Table 1 , filtered for a maximum spectral variability in $k(\lambda)$ of $10 \%$ with respect to the mean retrieved $k$. Biomass burning sites are "+" symbols, dust sites are squares. Only $5 \%$ of the particles dominated by the fine mode indicate $\mathrm{AAE}<1$, but $90 \%$ of the particles dominated by the coarse mode indicate $\mathrm{AAE}<1$.

\section{AAE for bimodal size distributions}

Since the AERONET product retrieves fine and coarse aerosol modes with the same refractive index, it is useful to include a second lognormal mode in the size distributions for the contour-style analysis of Fig. 2. This is accomplished in Fig. 3, where we have computed contours for bimodal aerosol size distributions with a real refractive index $n=1.49$, fine mode median radius $R_{\mathrm{fin}}=0.12 \mu \mathrm{m}$, coarse mode median radius $R_{\mathrm{crs}}=3.2 \mu \mathrm{m}$, fine mode standard deviation $\sigma_{\text {fin }}=0.38$, and coarse mode standard deviation $\sigma_{\mathrm{crs}}=0.75$. We vary the coarse volume fraction in this figure so that the effective radius increases from left to right. We have also included Level 2.0 AERONET retrievals for all of the sites in Table 1 (symbols), but we filter the data for $k(\lambda)$ that are constant with respect to wavelength (to within $10 \%$ ) in order to maintain consistency with the contours. This reduces our data set from 8011 retrievals to 989 retrievals. This also eliminates retrievals with substantial $\mathrm{BrC}$ fractions, because $\mathrm{BrC}$ has much higher $k$ values at $0.440 \mu \mathrm{m}$ than at the red and near-infrared retrieval wavelengths (e.g., see Fig. 1). Hematite also has a strong spectral dependence for $k$, with $\mathrm{d} k / \mathrm{d} \lambda<0$ at visible wavelengths, but it could be present in the retrievals of Fig. 3 if it is balanced with suitable quantities of goethite, which coexists with hematite in mineral dust and has the opposite spectral dependence at visible wavelengths (i.e., $\mathrm{d} k / \mathrm{d} \lambda>0$ ). 
Note how all of the AERONET data fall well below $k=$ 0.1 in Fig. 3, putting the data in a region with nearly vertical contour lines. The AERONET data are consistent with the contours, as gradients in the color of the points clearly vary horizontally but not vertically (in fact, the correlation of AAE and cvf for the data in Fig. 3 is $R=-0.863$ ). Varying the coarse volume fraction (cvf) at a constant $k$ in Fig. 3 has a substantial effect on AAE (about a factor of 2). The AERONET data indicate that AAE $<0.8$ is only achieved when the coarse volume fraction is greater than 0.5 (dark blue points in Fig. 3), indicating that the smallest AAE in this figure are not caused by carbonaceous aerosols. Thus, we conclude that AAE is quite sensitive to the relative fraction of fine and coarse mode aerosols when $k(\lambda)$ is spectrally invariant.

The $\mathrm{sC}$ volume fraction in an internal aerosol mixture is linearly related to the imaginary index of the mixture at the red and near-infrared wavelengths (as shown by Fig. 7 in Schuster et al., 2005), so $k_{\text {rnir }}$ is a surrogate for $\mathrm{sC}$ in the AERONET database. (Note that $k=k_{\text {rnir }}$ when $k$ is spectrally invariant, as in Fig. 3.) The contours in Fig. 3 indicate that varying $k$ at a constant coarse volume fraction does not alter the AAE for aerosols with $0.0005 \leq k<0.1$, which is consistent with the AERONET data in that figure. Thus, we can safely state that AAE is not sensitive to the volume fraction of $\mathrm{sC}$ in the AERONET retrievals when $k$ is spectrally invariant. This is discussed further in Sect. 8.

\section{AERONET AAOD and AAE products}

At this point, it is worthwhile to review some of the fundamentals of the AERONET retrieval algorithm (Holben et al., 1998, 2001; Dubovik and King, 2000; Dubovik et al., 2000). The AERONET radiometers measure aerosol optical depth by pointing a narrow-field-of-view radiometer directly at the sun. The instruments also scan azimuthally to measure sky radiances. Both the direct-beam and sky-radiance measurements are used as constraints in the AERONET inversion algorithm, which provides a wide variety of data products, including aerosol absorption optical depth (AAOD), complex refractive index, and single-scatter albedo at four wavelengths $(0.44,0.675,0.87$, and $1.02 \mu \mathrm{m})$. AERONET also provides AAE, which is computed from the AAOD product at the $0.44,0.675$, and $0.87 \mu \mathrm{m}$ wavelengths.

It is important to note that the absorption products like $\mathrm{AAOD}$ and AAE are not direct measurements; rather, the AERONET algorithm retrieves a size distribution and complex refractive index that is constrained by direct sun and sky radiance measurements, from which AAOD and AAE are computed. The size distribution is provided at 22 radii ranging from $r_{\mathrm{p}}=0.05$ to $15 \mu \mathrm{m}$, and the imaginary refractive index is allowed to vary from $k=0.0005$ to $k=0.5$. The algorithm uses Mie Theory to calculate the AAOD for spheres and uses T-matrix or geometrical optics theory to

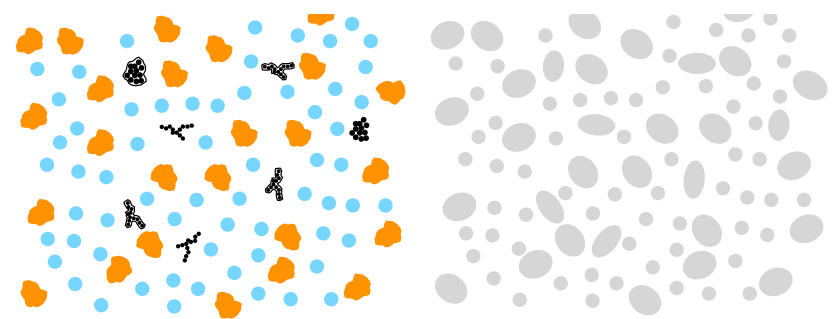

Figure 4. Left panel: a conceptual system of aerosols that contains scattering particles as well as a small fraction of absorbing carbon aggregates. Right panel: AERONET model of the same system of particles. Since all particles in the AERONET model have the same refractive index (and therefore the same color), the AERONET model disperses absorption amongst all particles.

calculate the AAOD for spheroids (Dubovik et al., 2002b, 2006). Additionally, the Level 2 data that we present in this document require aerosol optical depths $\mathrm{AOD} \geq 0.4$ at the $0.440 \mu \mathrm{m}$ wavelength. The data have been cloud screened and quality checked (Smirnov et al., 2000). The AOD is accurate to $\sim 0.01$ at the $0.440-1.020 \mu \mathrm{m}$ wavelengths (Eck et al., 1999). The accuracies of the Level 2.0 absorption products are estimated at $30-50 \%$ for the imaginary refractive index (Dubovik et al., 2000) and 0.1-0.6 for the AAE (Giles et al., 2012); the highest AAE uncertainties correspond to aerosol size distributions dominated by the coarse mode.

The AERONET algorithm also assumes that all particles in the atmosphere have the same complex refractive index (regardless of size), which is equivalent to assuming that all particles have identical composition (and all aerosol species are internally mixed). This assumption is necessary to achieve a unique solution, but it forces the absorption to be spread over all retrieved particle sizes, even when the absorption really occurs in only the smallest particles.

This last point is illustrated conceptually in Fig. 4. Here, the left panel shows a system of aerosols that contains scattering particles, as well as a small fraction of absorbing carbon aggregates. Unlike filter measurements that isolate the absorption of $\mathrm{sC}$ from the scattering of non-absorbing particles, the AERONET retrieval model assumes that all particles are equally absorbing (right panel of Fig. 4). Thus, the absorption of the small percentage of internally and externally mixed $\mathrm{sC}$ particles is effectively redistributed amongst all of the aerosol particles in the system.

This is important because it affects how we can interpret the data. For instance, we stated earlier that the maroon shaded region of Fig. 2 is appropriate for determining the AAE of open soot clusters, since soot monomers have radii less than $0.025 \mu \mathrm{m}$. This shaded region is also consistent with in situ measurements and the Rayleigh small particle limit for absorption. Nonetheless, AERONET can not report these particle sizes because they are smaller than the minimum allowed value in the AERONET retrieval algorithm. That is not to say that the AERONET measurements are not affected by 
these particles, though, as anything that has a significant impact on the radiation field at $\lambda=0.440-1.02 \mu \mathrm{m}$ will affect the AERONET retrievals.

Additionally, AERONET would never report a refractive index as high as the values in the maroon rectangle or the yellow square of Fig. 2, even if the algorithm allowed such high values. This is because these regions of Fig. 2 are only suitable for "pure" soot, which is typically a few percent of the total particulate matter in the atmosphere (Martins et al., 1998; Andreae, 2006; Adachi et al., 2010). AERONET refractive indices are typically $k \lesssim 0.04$, so open aggregates of $\mathrm{sC}$ would likely have $\mathrm{AAE}=1.2-1.4$ (maroon circles with $k \leq 0.04$ in Fig. 2). We also note that $k \lesssim 0.04$ corresponds to $5 \% \mathrm{sC}$ or less in Fig. 2.

The redistribution of absorption shown conceptually in Fig. 4 also forbids us from assuming that all $\mathrm{sC}$ absorption is always located in the fine mode, because the absorption that the AERONET algorithm redistributes to the coarse mode can be substantial. For instance, the coarse mode volume fractions are $0.29-0.44$ and the imaginary refractive indices are 0.01-0.02 at the biomass burning sites in the AERONET climatology (Dubovik et al., 2002a). If we naively assume that carbonaceous aerosols are not responsible for any coarse mode absorption at these sites, then all of the coarse mode absorption has to be caused by absorbing minerals in dust (i.e., hematite and goethite). If this is indeed the case, then it would require $\sim 15 \%$ hematite or goethite by volume to achieve $k=0.02$ at the $0.700 \mu \mathrm{m}$ wavelength (assuming $k=0.13$ for hematite and volume averaging of refractive indices for this simple exercise). Both hematite and goethite have densities that are about twice as large as other minerals, so the corresponding iron oxide mass mixing ratio would be $30 \%$ (Schuster et al., 2016). Since mass fractions of hematite in mineral dust are typically less then $5 \%$ (Lafon et al., 2004; Linke et al., 2006; Kandler and Schütz, 2007; Formenti et al., 2008; Kandler et al., 2009; Klaver et al., 2011), some carbon absorption must be present in the coarse mode of these climatologies (this is particularly important since the coarse mode fractions are so high). We emphasize that carbonaceous aerosols do not have to actually exist in the coarse mode; rather, we are pointing out that some of the fine mode absorption is artificially redistributed to the coarse mode in the AERONET retrievals (because all particles are assumed to have the same refractive index).

Now, one might argue that the coarse aerosol mode is less optically efficient than the fine aerosol mode, and that a large coarse volume fraction is not necessarily optically significant. Hence, we evaluated the coarse mode contribution to the aerosol optical depth at the South American sites of Table 1 during the biomass burning season (August and September), where we found a median coarse mode volume fraction of 0.4 . The corresponding median coarse mode optical depth fractions (i.e., $\mathrm{AOD}_{\mathrm{crs}} / \mathrm{AOD}_{\text {tot }}$ ) are 0.06, $0.14,0.24$, and 0.33 at the $0.440,0.674,0.870,1.020 \mu \mathrm{m}$ wavelengths. Additionally, the coarse mode is responsible for more than $10 \%$ of $\mathrm{AOD}(440)$ in $30 \%$ of the cases and more than $20 \%$ of $\operatorname{AOD}(674)$ in $35 \%$ of the cases. Hence, although the coarse mode optical depth fraction is much smaller than the coarse mode volume fraction, coarse mode aerosols can still be optically significant.

We note that the assumption that all particles are internally mixed and have the same refractive index was not an arbitrary choice in the design of the retrieval algorithm. Rather, this constraint was implemented after extensive testing indicated that a unique solution was not possible when allowing two (or more) refractive indices. Sensitivity studies at that time showed that constraining the algorithm to a single refractive index for all particles produced values that are intermediate of the fine and coarse mode refractive indices (Dubovik et al., 2000, Fig. 10).

There are some additional constraints associated with the AERONET retrieval model of Fig. 4. (1) We can not use sophisticated models that account for the aggregate fractal dimensions or even core-shell configurations to describe the AAE produced by AERONET, since these models are inconsistent with the AERONET retrieval model. (2) Absorption is not additive for internal mixtures, so we can not assume that the total aerosol absorption is the sum of the absorption associated with individual species (i.e., $C_{\text {abs }} \neq \sum_{i} C_{\text {abs }}^{i}$ ). This concept is violated in the AAE approach of Bahadur et al. (2012), Chung et al. (2012b), and Xu et al. (2013). This is particularly troublesome when the AAE approach is applied at biomass burning sites, as $\mathrm{sC}$ and $\mathrm{BrC}$ occupy the same particle size range (i.e., they both occupy the fine aerosol mode). Since AERONET assumes equal refractive indices for all particles, our only choice is to use models that assume that small amounts of $\mathrm{sC}$ (or another absorber) exist in every aerosol particle; we must also assume that the particles are shaped like spheres and spheroids. The use of optical models that do not adhere to these assumptions risk severing the link to the radiation measurements that are the basis (and the strength) of the AERONET retrievals.

\section{AAE for spectrally variant $k$}

AERONET provides the imaginary refractive index $k(\lambda)$ at four wavelengths $(0.440,0.675,0.870,1.020 \mu \mathrm{m})$. When soot carbon is the only absorbing aerosol in the atmosphere, we expect the AERONET retrieval to indicate the same $k(\lambda)$ at all four wavelengths (since $\mathrm{sC}$ has a spectrally invariant $k$ at the red and near-infrared wavelengths, as shown in Fig. 1). However, $\mathrm{BrC}$ and hematite have greater imaginary indices at the $0.440 \mu \mathrm{m}$ wavelength $\left(k_{440}\right)$ than at the mean of the red and near-infrared wavelengths $\left(k_{\text {rnir }}\right)$. Similarly, goethite has a smaller imaginary index at $0.440 \mu \mathrm{m}$ than at $0.700 \mu \mathrm{m}$ (Bedidi and Cervelle, 1993). Thus, we can use the spectral variability of $k$ in the AERONET data set to deduce the presence of $\mathrm{BrC}$, hematite, and goethite in the atmosphere. 


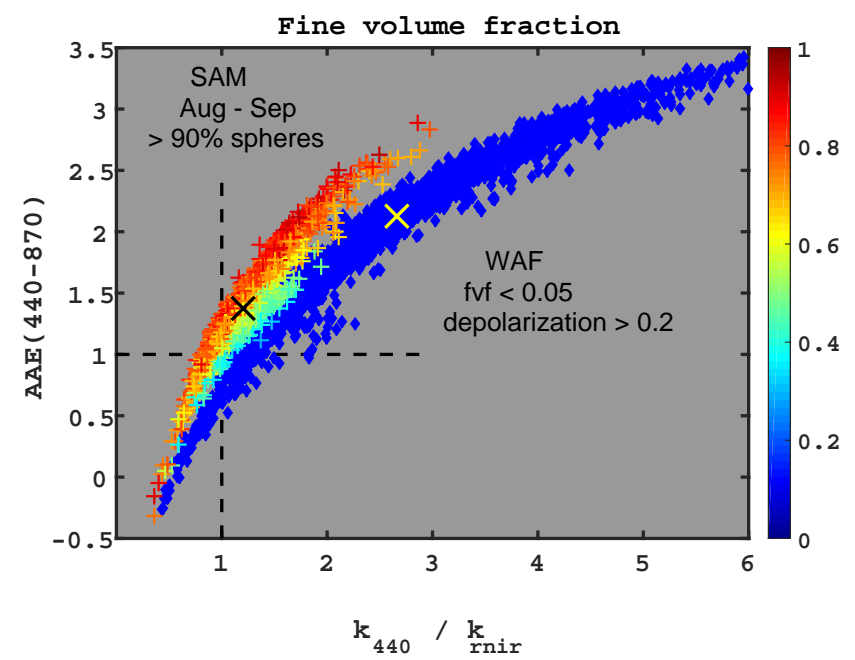

Figure 5. Absorption Ångström exponent vs. the $k_{440} / k_{\text {rnir }}$ imaginary refractive index ratio, color-coded with the fine volume fraction. Upper branch of "+" symbols is the South American sites during the biomass burning season when more than $90 \%$ of the retrievals are spheres; the lower branch of diamond symbols is dust at the West African sites when the fine volume fractions are less than 0.05 and the linear depolarization ratios are greater than 0.2. Medians of the two branches are denoted by the " $x$ " symbols.

We present the spectral variability of $k(\lambda)$ in West Africa and South America as $k_{440} / k_{\text {rnir }}$ in Fig. 5, which shows AAE as a function of $k_{440} / k_{\text {rnir }}$. Both West African and South American data from the sites in Table 1 are shown here, but we limit the West African fine volume fraction to $\mathrm{fvf}<0.05$ and linear depolarizations to $\mathrm{dp}>0.2$ at the $532 \mathrm{~nm}$ wavelength, in an effort to restrict the data to pure dust. (Schuster et al., 2012, and Dubovik et al., 2006, provide the methodology for computing the linear depolarization ratio from the AERONET size distributions, complex refractive index, percentage of spheres, and distribution of axis ratios.) We also limit the South American data to the peak of the biomass burning season (August-September) and require these retrievals to have more than $90 \%$ spheres (in an effort to eliminate dust). Here, we see that AAE is well correlated with $k_{440} / k_{\text {rnir }}$ for both biomass burning and dust aerosols, with a linear correlation of $R \geq 0.939$ in both cases.

Atmospheric aerosols with substantial $\mathrm{BrC}$ or hematite absorption have large $k_{440} / k_{\text {rnir }}$ and are located in the upper right quadrant of Fig. 5. Aerosols that are dominated by $\mathrm{sC}$ with little spectral variability have $k_{440} / k_{\mathrm{rnir}} \simeq 1$ and are located near the vertical dashed line in Fig. 5. Finally, aerosols that are dominated by absorbing particles with elevated imaginary indices at red and near-infrared wavelengths have $k_{440} / k_{\text {rnir }}<1$ and are located to the left of the vertical dashed line.

Note that there are clearly two branches of data in Fig. 5. The upper branch of small "+" symbols are the South American biomass burning sites; the lower branch of small dia-
Table 2. Percentage of retrievals with $\mathrm{AAE} \leq 1, k_{440} \leq k_{\text {rnir }}$ and $k_{440} \leq k_{\text {rnir }}$ when AAE $\leq 1$ at the West African (waf), Middle Eastern (mea), southern African (saf), and South American (sam) sites of Table 1 .

\begin{tabular}{lrrrr}
\hline Constraint & waf & mea & saf & sam \\
\hline $\mathrm{AAE}<1$ & 11 & 13 & 16 & 13 \\
$k_{440} \leq k_{\text {rnir }}$ & 4 & 6 & 32 & 21 \\
$k_{440} \leq k_{\text {rnir }}$, given $\mathrm{AAE} \leq 1$ & 39 & 44 & 97 & 94 \\
\hline
\end{tabular}

monds are the West African dust sites. Both branches are color-coded according to fine volume fraction, but we have filtered the West African data for fvf $<0.05$, so all of those points are the same color. The median for the South American biomass burning data is denoted by the black " $\times$," and the median for the West African dust data is denoted by the yellow " $\times$." Note that the carbonaceous aerosols of South America have higher AAE than the dust aerosols of West Africa for any given value of $k_{440} / k_{\text {rnir }}$ on the abscissa; this is because we have limited the dust particles to $\mathrm{fvf}<0.05$ in that figure, so the carbonaceous particles are much smaller than the dust particles. This is consistent with Figs. 2 and 3 , which show that larger particles produce smaller AAE for a given value of $k$.

It is interesting to discuss the points with $\mathrm{AAE}<1$ in the bottom two quadrants of Fig. 5, which includes $16 \%$ of the South American retrievals and $11 \%$ of the West African retrievals. Note that the carbonaceous aerosols of South America essentially require $k_{440} / k_{\text {rnir }}<1$ when $\mathrm{AAE}<1$, as very few of these retrievals are located in the lower right quadrant of Fig. 5. In fact, $94 \%$ of the South American data with $\mathrm{AAE}<1$ also indicates $k_{440} / k_{\mathrm{rnir}}<1$. This is not the case for the dust retrievals, which show that only $39 \%$ of the retrievals indicate $k_{440} / k_{\text {rnir }}<1$ when $\mathrm{AAE}<1$. We obtained similar results at the southern African and Middle Eastern sites, as summarized in Table 2 .

So AAE $<1$ essentially requires $k_{440}<k_{\text {rnir }}$ when fine particles dominate the aerosol size distribution, and few atmospheric aerosols are known to exhibit this behavior. The mineral goethite is prevalent in dust and indicates this spectral behavior (Bedidi and Cervelle, 1993, and Fig. 1), but large quantities of this mineral at the biomass burning sites of South America do not seem plausible (especially since we require at least $90 \%$ spheres for the retrievals in this figure). Thus, we seek another material that could cause $k_{440}<k_{\text {rnir }}$ at the biomass burning sites. Carbonaceous aerosols are an obvious possibility, but $k_{440}>k_{\text {rnir }}$ for $\mathrm{BrC}$ (Fig. 1). Additionally, Bond and Bergstrom (2006) did an extensive literature review of many refractive indices available for $\mathrm{sC}$, and they concluded that the data indicating a spectral dependence for $\mathrm{sC}$ at visible wavelengths could also be explained with spectrally invariant refractive indices (within the measurement uncertainty). They also recommended using 
a wavelength-independent $k$ for $\mathrm{sC}$ at visible wavelengths, and the Bond et al. (2013) report even included a wavelengthindependent refractive index as part of their definition of $\mathrm{sC}$ (Bond et al., 2013, Sect. 3.2.1).

On the contrary, Bergstrom et al. (2007) mentioned that "there is no physical reason why the index of refraction for LAC ( $\mathrm{sC}$ ) should be constant with wavelength." For instance, Jäger et al. (1998) measured the refractive index of pelletized cellulose that were pyrolyzed at temperatures ranging from 400 to $1000^{\circ} \mathrm{C}$. The samples became graphitized when pyrolyzed at $1000^{\circ} \mathrm{C}$, and the imaginary index increased from 0.68 to 0.78 as wavelength increased from 0.400 to $1.0 \mu \mathrm{m}$ for the graphitized pellets. However, it is important to note that their un-graphitized samples pyrolyzed at $600^{\circ} \mathrm{C}$ also exhibited $\mathrm{d} k / \mathrm{d} \lambda>0$ throughout the visible range, contrary to the behavior of BrC shown in Fig. 1. Additionally, both their 400 and $600{ }^{\circ} \mathrm{C}$ cellulose pyrolysis indicated $k \gtrsim 0.36$ throughout the visible spectrum, which is much higher than the conventional values for $\mathrm{BrC}$ shown in Fig. 1. Thus, it is not clear that the cellulose samples of Jäger et al. (1998) represent the soot carbon (or $\mathrm{BrC}$ ) aerosols found in the atmosphere.

Nonetheless, Schnaiter et al. (2005) also deduced a strong spectral dependence for diesel soot, with the imaginary index ranging from 0.9 to 1.1 between the 0.450 and $0.700 \mu \mathrm{m}$ wavelengths. Chung et al. (2012a) downscaled the Schnaiter et al. (2005) values to match Moffet and Prather (2009) at $\lambda=0.550 \mu \mathrm{m}$, which resulted in $k$ values that range from 0.64 at $\lambda=0.45 \mu \mathrm{m}$ to 0.78 at $\lambda=0.700 \mu \mathrm{m}$. This strong spectral dependence of $k$ results in $\mathrm{AAE}<1$, even for small particles.

Instrument and/or algorithm limitations can also lead to $k_{440} / k_{\text {rnir }}<1$ in the AERONET database (Giles et al., 2011, 2012). For instance, AERONET uses SCIAMACHY satellite data from 2003 to 2005 to compute monthly climatological $\mathrm{NO}_{2}$ absorption at the $0.440 \mu \mathrm{m}$ wavelength (http://aeronet. gsfc.nasa.gov/new_web/Documents/version2_table.pdf).

These climatological $\mathrm{NO}_{2}$ absorption optical depths are used to correct the reported AOD at the $0.440 \mu \mathrm{m}$ wavelength. However, if the climatological $\mathrm{NO}_{2}$ concentration happens to be greater than the actual $\mathrm{NO}_{2}$ concentration present during a retrieval, then the corrected AOD at $0.440 \mu \mathrm{m}$ will actually be an overcorrection, and the resulting AOD will be biased low of the true value. When this is the case, the algorithm might reduce the retrieved aerosol absorption at the $0.440 \mu \mathrm{m}$ wavelength in order to compensate for the excess $\mathrm{NO}_{2}$ absorption. However, the climatological $\mathrm{NO}_{2}$ concentrations at the dust and biomass burning sites of this study are typically smaller than the $\mathrm{NO}_{2}$ concentrations found in large metropolitan regions, so it is not clear that the $\mathrm{NO}_{2}$ correction is adversely affecting the retrievals in the left quadrants of Fig. 5.

\section{Using AAE to retrieve component AAODs}

Now that we have a good understanding of how the AERONET retrieval algorithm interprets aerosol absorption, as well as the behavior of AAE within the constraints of the AERONET retrieval assumptions, and the sensitivity of AAE to the wavelength dependence of $k$, we can examine the AAE approach for separating carbonaceous AAOD from dust AAOD. The AAE approach assumes that carbonaceous (c) and dust (d) aerosols are externally mixed, and therefore the absorption of these two species are additive (Chung et al., 2012b; Bahadur et al., 2012; Xu et al., 2013):

$\xi=\xi_{\mathrm{c}}+\xi_{\mathrm{d}}$.

Then Eq. (1) is applied to each absorbing aerosol component:

$\xi(1) \lambda^{-\mathrm{AAE}}=\xi_{\mathrm{c}}(1) \lambda^{-\mathrm{AAE}_{\mathrm{c}}}+\xi_{\mathrm{d}}(1) \lambda^{-\mathrm{AAE}_{\mathrm{d}}}$.

If $\mathrm{AAE}_{\mathrm{c}}$ and $\mathrm{AAE}_{\mathrm{d}}$ are known, measurements of $\xi$ at two wavelengths provide enough information to solve Eq. (5) for $\xi_{\mathrm{c}}(1)$ and $\xi_{\mathrm{d}}(1)$, which can be used in a component version of Eq. (1) to solve for $\xi_{\mathrm{c}}(\lambda)$ and $\xi_{\mathrm{d}}(\lambda)$.

Once $\xi_{\mathrm{c}}$ has been obtained in this way, Chung et al. (2012b) assumes that $\mathrm{BrC}$ and $\mathrm{sC}$ are also externally mixed and uses a similar analysis to further partition the carbonaceous aerosol absorption into $\mathrm{SC}$ and $\mathrm{BrC}$ components:

$\xi_{\mathrm{c}}(1) \lambda^{-\mathrm{AAE}_{\mathrm{c}}}=\xi_{\mathrm{sC}}(1) \lambda^{-\mathrm{AAE}_{\mathrm{sC}}}+\xi_{\mathrm{BrC}}(1) \lambda^{-\mathrm{AAE}_{\mathrm{BrC}}}$.

However, since $\mathrm{AAE}_{\mathrm{c}}, \mathrm{AAE}_{\mathrm{SC}}$, and $\mathrm{AAE}_{\mathrm{BrC}}$ are fixed by climatology in the Chung et al. (2012b) approach, the ratio of brown carbon to soot carbon optical depths (i.e., $\xi_{\mathrm{BrC}} / \xi_{\mathrm{sC}}$ ) is also mathematically fixed to climatological values by Eq. (6) (i.e., Chung et al., 2012b, Eq. 2). Since the Chung et al. (2012b) approach recognizes four climatological regions (see their Fig. S1), only four values of $\xi_{\mathrm{BrC}} / \xi_{\mathrm{sC}}$ are possible. Bahadur et al. (2012) uses a three-wavelength approach that does not have this limitation.

Authors who use the AAE approach postulate that each absorbing aerosol has a unique AAE and that the AAOD can therefore be partitioned to each species on the basis of AAE alone. Chung et al. (2012b) derived values for $\mathrm{AAE}_{\mathrm{c}}$ and $\mathrm{AAE}_{\mathrm{d}}$ from the AERONET database in regions and seasons with minimal mixing of the two aerosol types. They found that $\mathrm{AAE}_{\mathrm{d}}=2.4$ is an average value for dust, and the regionspecific $\mathrm{AAE}_{\mathrm{c}}$ for carbonaceous aerosols ranges from 0.84 to 1.16. They also postulate $\mathrm{AAE}_{\mathrm{SC}}=0.5$ and $\mathrm{AAE}_{\mathrm{BrC}}=4.8$. Bahadur et al. (2012) used a similar approach and obtained $\mathrm{AAE}_{\mathrm{SC}}=0.55$ or 0.83 , depending upon wavelength range.

\subsection{Theoretical issues with the AAE approach}

Note that the AAE approach abandons the small particle limit of $\mathrm{sC}$, in favor of using a much lower value of $\mathrm{AAE}_{\mathrm{SC}}$ than $\mathrm{AAE}_{\mathrm{SC}}=1$. Chung et al. (2012b) claim that $\mathrm{AAE}<1$ is caused by coated $\mathrm{sC}$, based upon the theoretical calculations 


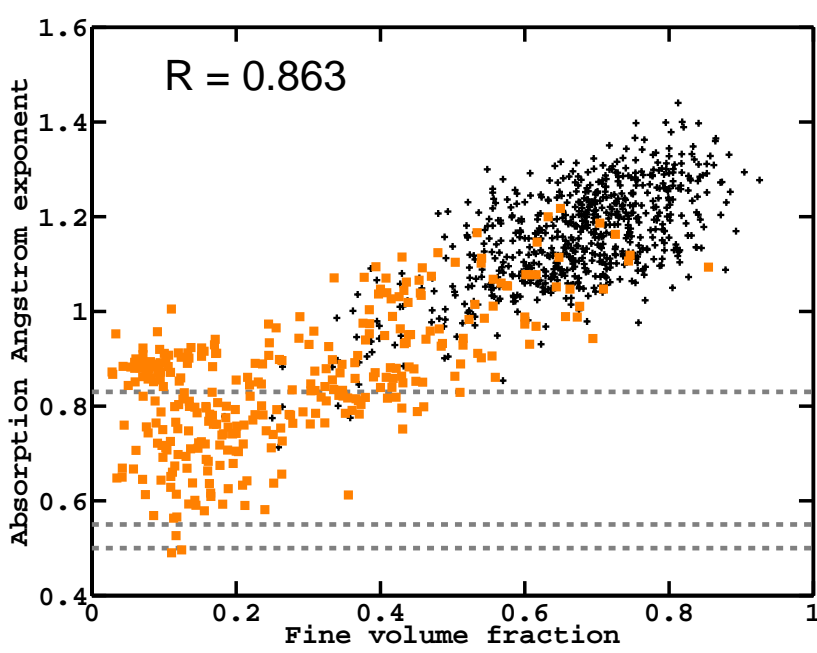

Figure 6. AAE(440-870) vs. fvf at all AERONET sites of Table 1, filtered for a maximum spectral variability in $k(\lambda)$ of $10 \%$ with respect to the mean retrieved $k$. Orange squares are dust sites and black "+" symbols are biomass burning sites. Dashed lines denote the $\mathrm{AAE}_{\mathrm{SC}}$ postulated by Chung et al. (2012b) and Bahadur et al. (2012).

of Chung et al. (2012a). However, Chung et al. (2012a) uses a spectrally varying refractive index for soot carbon, which is not consistent with the Bond et al. (2013) definition; this alone can cause $\mathrm{AAE}<1$, regardless of mixing state or particle size.

On the contrary, other authors have computed AAE using wavelength-independent refractive indices for soot carbon cores coated with non-absorbing shells and have found that the AAE increases to values as high as about 1.6 as the coating thickness increases (as long as the core diameters are less than $\sim 0.1 \mu \mathrm{m}$; Gyawali et al., 2009; Lack and Cappa, 2010). Additionally, Bond (2001) and Gyawali et al. (2009) also computed the AAE for uncoated particles with spectrally invariant $k(\lambda)$ and found that AAE $<1$ could only be achieved for particles with diameters greater than $\sim 0.1 \mu \mathrm{m}$. This is also consistent with our computations shown in Fig. 2.

Computations based upon mono-modal lognormal size distributions do not necessarily represent the bimodal aerosol size distributions provided in the AERONET database, though. Fortunately, we can also assess the AAE of $\mathrm{sC}$ in the AERONET retrievals by screening for spectrally invariant $k$, since $\mathrm{sC}$ is the only absorbing aerosol with $\mathrm{d} k / \mathrm{d} \lambda \sim 0$ at the AERONET wavelengths (per Fig. 1). Thus, we re-plot the data of Fig. 3 in Fig. 6, again using squares for the dust sites and "+" symbols for the biomass burning sites. The dashed lines in Fig. 6 denote the $\mathrm{AAE}_{\mathrm{SC}}$ values postulated for the AAE approach (Chung et al., 2012b; Bahadur et al., 2012).

It is immediately noticeable that $\mathrm{AAE}$ has a large range of values depending upon the fine mode fraction. Values of $\mathrm{AAE}<0.83$ only occur when fvf $<0.5$, so the value of $\mathrm{AAE}_{\mathrm{SC}} \sim 0.5$ used in the AAE approach is unlikely to be associated with pure $\mathrm{sC}$. We speculate that $\mathrm{AAE}<0.83$ is caused by a balance of hematite and goethite for data dominated by the coarse mode in Fig. 6 and that the AAE approach overestimates carbonaceous aerosol absorption for these cases.

Additionally, the relatively large AAE at the biomass burning sites in Fig. 6 is not caused by $\mathrm{BrC}$ (since we have screened the data for spectrally invariant $k$ to within $10 \%$ ); rather, it is caused by the AAE enhancement associated with the internal mixing of soot carbon. Since the $\mathrm{AAE}_{\mathrm{SC}}$ postulated by Chung et al. (2012b) and Bahadur et al. (2012) is substantially lower than all of the AAE at the biomass burning sites, the AAE approach underestimates the amount of $\mathrm{sC}$ absorption and overestimates the amount of $\mathrm{BrC}$ absorption for these cases.

Additionally, 94-97\% of the biomass burning data in Fig. 5 and Table 2 with $\mathrm{AAE}<1$ also has $k_{440} / k_{\text {rnir }}<1$. Thus, the presumption that $\mathrm{AAE} \ll 1$ indicates pure $\mathrm{sC}$ also requires that pure $\mathrm{SC}$ has a spectrally variant imaginary index with $\mathrm{d} k / \mathrm{d} \lambda>0$ (or that this pure $\mathrm{sC}$ is located in the coarse mode). That is, we can not assume that $\mathrm{AAE}_{\mathrm{SC}}<1$ and $\mathrm{d} k / \mathrm{d} \lambda=0$ for pure $\mathrm{sC}$, as these assumptions are mutually inconsistent.

Also note that Eqs. (4) and (6) inherently assume that AAOD is additive, which requires that all absorbers are externally mixed. It is well known that a substantial portion of $\mathrm{sC}$ aerosols are internally mixed with other aerosols (e.g., Martins et al., 1998; Schwarz et al., 2008a, b) and that sC and $\mathrm{BrC}$ are produced nearly simultaneously during biomass burning. Thus, it is likely that a substantial portion of $\mathrm{sC}$ is coated with $\mathrm{BrC}$ when $\mathrm{BrC}$ is present. Additionally, application of Eq. (5) requires the assumption that $\mathrm{AAE}_{\mathrm{c}}$ is not dependent upon the carbonaceous aerosol mixing state (Bahadur et al., 2012), which is clearly not the case (per Figs. 2 and 3, as well as Bond, 2001; Gyawali et al., 2009; Lack and Cappa, 2010; Lack and Langridge, 2013). Finally, the external mixing assumption of the AAE method is inconsistent with the internal mixing assumption used to compute AAE in the AERONET retrievals (as outlined in Sect. 6).

\subsection{Practical issues with applying the AAE approach}

We can get an idea of whether an aerosol retrieval is dust or carbonaceous aerosols by plotting the AAE vs. fvf, as shown in Fig. 7. (This is similar to the Ångström matrix presented by Cazorla et al., 2013; see also Clarke et al., 2007; Russell et al., 2010; Bahadur et al., 2012; Giles et al., 2012.) The West African sites of Table 1 are shown as maroon squares, and the South American biomass burning sites are shown as gray circles. We eliminate dust from the South American data set by requiring more than $90 \%$ of those retrieved particles to be spheres. West African data that are heavily influenced by mineral dust have linear depolarization ratios greater than 0.2 , which we highlight as orange diamonds. The remaining maroon points are mixtures of dust and carbonaceous 


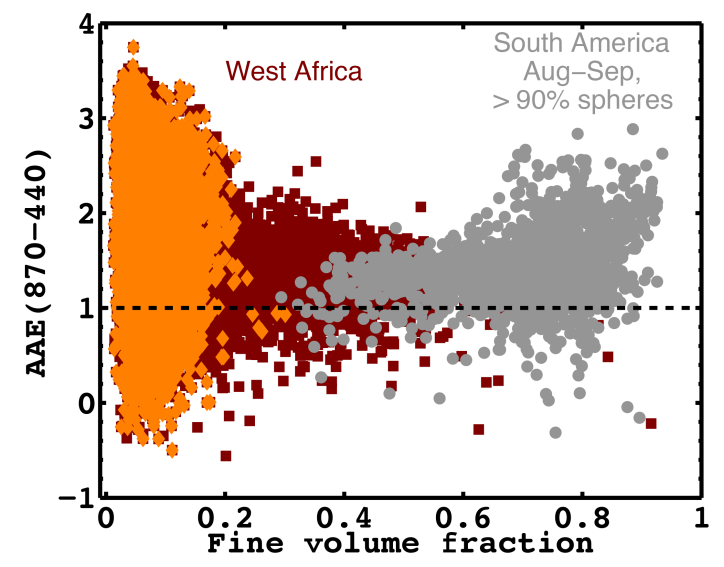

Figure 7. Absorption Ångström exponent (AAE) vs. fine volume fraction during the South American biomass burning season (gray circles) and at the West African sites (maroon squares). The South American data are limited to retrievals with more than $90 \%$ spheres. West African data with linear depolarization ratios greater than 0.2 are denoted by orange diamonds.

aerosols that are common for the West African sites during the winter months. Figure 7 demonstrates that fvf can be used to separate carbonaceous aerosols from aerosols dominated by dust. Points in between $\mathrm{fvf} \gtrsim 0.2$ and $\mathrm{fvf} \lesssim 0.6$ are problematic because they are a mixture of carbonaceous aerosols and mineral dust.

Inspection of Fig. 7 reveals a problem with the AAE approach, though. The AAE approach classifies aerosol systems with $0.84 \leq \mathrm{AAE} \leq 1.16$ as carbonaceous (Chung et al., 2012b); thus, retrievals that produce AAE in this range of values will be classified as carbonaceous, regardless of the fvf. This is inappropriate for the highly depolarized aerosols that occur when fvf $\lesssim 0.2$ (clearly these particles contain substantial amounts of mineral dust, since the depolarizations are so high and the fine volume fractions are so low). Additionally, the AAE parameter cannot determine the degree of mixing of the dust aerosols on the left side of Fig. 7 with the carbonaceous aerosols on the right side of this figure; AAE can only discriminate microphysical properties with gradients along the vertical axis in Fig. 7. Likewise, all retrievals with $\mathrm{AAE}<0.84$ are required to be $100 \%$ carbonaceous in the AAE scheme, which can not be the case.

Since the AAE approach postulates that aerosol columns with $\mathrm{AAE} \ll 1$ are dominated by $\mathrm{sC}$, it is important to assess the composition of aerosol systems with small AAE. Figure 8 provides cumulative histograms of the fvf, dp, and AE for the West African sites when AAE $\leq 1.0$, which constitutes $11 \%$ of successful Level 2.0 retrievals in that region. Here, we see that $86 \%$ of the fvf are less than $0.2,56 \%$ of the depolarization ratios are greater than 0.2 , and $94 \%$ of the $\mathrm{AE}$ are less than 1.0. This indicates that most of the West African data with $\mathrm{AAE} \leq 1.0$ are dominated by coarse mode dust (not $\mathrm{sC}$ ) and that AAE cannot be used to separate dust from $\mathrm{sC}$. This

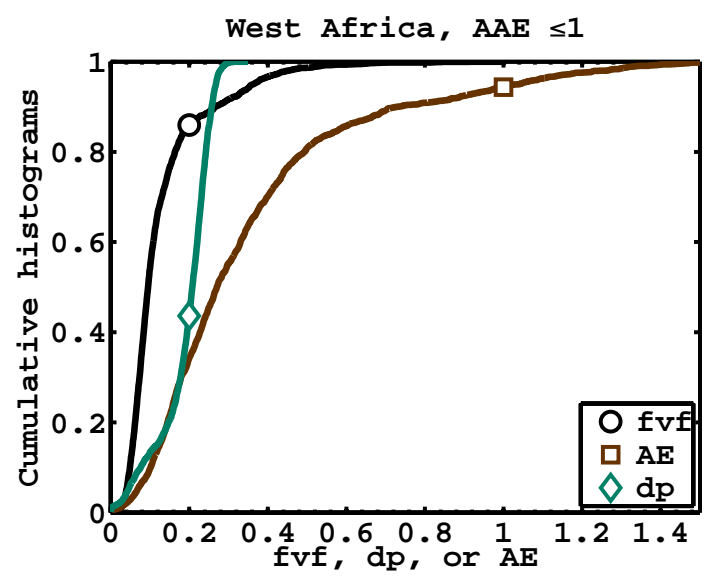

Figure 8. Cumulative histograms for the fine volume fraction (fvf), linear depolarization ratio (dp), and Ångström exponent (AE) at the West African sites; subsampled for AAE $\leq 1.0$, which is $11 \%$ of successful Level 2.0 retrievals. The symbols indicate that $86 \%$ of the fvf are less than $0.2,56 \%$ of the dp are greater than 0.2 , and $94 \%$ of the AE are less than 1.0. This indicates that most of the West African data with $\mathrm{AAE} \leq 1$ are dominated by coarse mode dust and that low AAE does not indicate pure $\mathrm{sC}$.

is consistent with Russell et al. (2014) (their Fig. 6) and Giles et al. (2012) (also their Fig. 6), both of which show a wide range of AAE for dust aerosols and substantial overlap of the dust and biomass burning AAE histograms. Thus, the AAE scheme overestimates carbonaceous aerosol absorption when $\mathrm{AAE} \lesssim 1$

\section{Conclusions}

We provided a detailed discussion about the AAE product available in the AERONET database, noting that this product is computed from retrieved size distributions and complex refractive indices. We also noted that particles are necessarily assumed to be internally mixed in the AERONET retrieval algorithm, and this assumption requires one to interpret the AERONET AAE product differently than one would interpret in situ AAE measurements. We provided theoretical calculations of AAE for mono-modal and bimodal size distributions with spectrally invariant imaginary refractive indices $k(\lambda)$, and we found that the AAE varies from 1 to more than 1.4 for fine mode particles having $k$ values consistent with the AERONET retrievals.

Although the analysis presented in this document mainly applies to the AERONET retrievals, the scientific community should exercise caution when analyzing in situ data as well. Soot carbon particles that are internally mixed with other aerosol species do not necessarily maintain $\mathrm{AAE}=1$. Additionally, measurement techniques that require dry aerosols may alter the AAE during the drying process (i.e., hygroscopic coatings may evaporate off of $\mathrm{sC}$ particles, thereby 
changing the $\mathrm{sC}$ mixing state from internal to external). Finally, although $\mathrm{AAE}=1$ may be suitable for open soot clusters with small primary spherules (radii $\lesssim 0.025 \mu \mathrm{m}$ ), compact clusters with median effective radii greater than about $0.1 \mu \mathrm{m}$ may have AAEs close to 0.6 ; thus, variable $\mathrm{sC}$ morphology must also be taken into account when analyzing in situ AAE.

The theoretical analysis as well as an analysis of spectrally invariant AERONET data indicated that AAE is not sensitive to the imaginary refractive indices in the AERONET database; thus, it is not sensitive to the proportion of soot carbon in the AERONET retrievals. We also find that the AAE is highly correlated with the coarse volume fraction for spectrally invariant AERONET data $(R=-0.863)$ and that the size distributions dominated by coarse mode particles have the lowest AAE values.

Authors who attempt to speciate absorbing aerosols on the basis of $\mathrm{AAE}$ alone have assumed that $\mathrm{AAE} \ll 1$ is unique to sC. However, we subsampled the AERONET retrievals for $\mathrm{AAE} \leq 1$ in a region where mixtures of dust and carbonaceous aerosols are common (West Africa) and found that $86 \%$ of the fine volume fractions are less than $0.2,56 \%$ of the depolarizations are greater than 0.2 , and $94 \%$ of the Ångström exponents are less than 1.0. Clearly AAE $\leq 1$ is more likely to be dominated by dust than by carbonaceous aerosols when these two species are mixed. Additionally, we found that $\mathrm{AAE}<1$ only occurs at the South American biomass burning sites when a substantial coarse mode is present in the volume size distribution ( $\mathrm{fvf}<0.5$ ) or when $k_{440}<k_{\text {rnir }}$; neither of these conditions are consistent with the definition of sC described in Bond et al. (2013). Hence, the assumption that $\mathrm{AAE} \ll 1$ for $\mathrm{sC}$ is also inconsistent with the definition of sC in Bond et al. (2013).

We discussed other explanations for $k_{440}<k_{\text {rnir }}$ in the AERONET data product. One possibility for mineral aerosols is the presence of goethite, which has a $k(\lambda)$ that increases throughout the visible spectrum and gives some dust a yellowish tint. (An increase in $k(\lambda)$ with respect to wavelength is not required to achieve $\mathrm{AAE}<1$ for coarse mode aerosols, however.) It is also possible that the imaginary refractive index of $\mathrm{sC}$ does indeed increase with respect to wavelength at visible and near-infrared wavelengths (as in Schnaiter et al., 2005). Other instrument and algorithm issues may also cause $k_{440}<k_{\text {rnir }}$.

Even if the scientific community were to universally adopt the notion that $\mathrm{d} k_{\mathrm{SC}} / \mathrm{d} \lambda>0$ for $\mathrm{sC}$ at visible and nearinfrared wavelengths, though, the external mixing assumption of the AAE approach abandons the internal mixing assumption required to produce the AERONET AAE product. Thus, it is not clear that the AAE approach maintains a viable link to the radiances measured by the AERONET instruments. This is important, because the link to the radiation field is the strength of the AERONET retrievals, and we cannot claim a constrained retrieval without it.
Ultimately, the aerosol community can not postulate that retrievals with $\mathrm{AAE} \ll 1$ in the AERONET database are primarily caused by soot carbon. The absorption Ångström exponent is not sensitive to the amount of $\mathrm{SC}$ in the AERONET retrievals, and it is sensitive to particle size and the spectral dependence of $k(\lambda)$.

Acknowledgements. This material was supported by the National Aeronautics and Space Administration under the NASA Glory Science Team, issued through the Science Mission Directorate, Earth Science Division. Oleg Dubovik was supported by the Labex CaPPA project involving several research institutions in Nord-Pasde-Calais, France. Antti Arola acknowledges support from the Academy of Finland (through the project number 264242). We appreciate the efforts of the 29 AERONET and PHOTONS (Service d'Observation from LOA/USTL/CNRS) principal investigators and the entire AERONET and PHOTONS teams for obtaining, processing, documenting, and disseminating their respective data sets. Finally, we thank the anonymous reviewers for their time and effort.

Edited by: P. Formenti

\section{References}

Adachi, K., Chung, S., and Buseck, P.: Shapes of soot aerosol particles and implications for their effects on climate, J. Geophys. Res., 115, D15206, doi:10.1029/2009JD012868, 2010.

Andreae, M.: Aerosols before pollution, Science, 315, 50-51, 2006.

Andreae, M. O. and Gelencsér, A.: Black carbon or brown carbon? The nature of light-absorbing carbonaceous aerosols, Atmos. Chem. Phys., 6, 3131-3148, doi:10.5194/acp-6-3131-2006, 2006.

Arola, A., Schuster, G., Myhre, G., Kazadzis, S., Dey, S., and Tripathi, S. N.: Inferring absorbing organic carbon content from AERONET data, Atmos. Chem. Phys., 11, 215-225, doi:10.5194/acp-11-215-2011, 2011.

Bahadur, R., Praveen, P., Xu, Y., and Ramanathan, V.: Solar absorption by elemental and brown carbon determined from spectral observations, P. Natl. Acad. Sci. USA, 109, 17366-17371, doi:10.1073/pnas.1205910109, 2012.

Bedidi, A. and Cervelle, B.: Light scattering by spherical particles with hematite and goethitelike optical properties: effect of water impregnation, J. Geophys. Res., 98, 11941-11952, 1993.

Bergstrom, R., Russell, P., and Hignett, P.: Wavelength dependence of the absorption of black carbon particles: Predictions and results from the TARFOX experiment and implications for the aerosol single scattering albedo, J. Atmos. Sci., 59, 567-577, 2002.

Bergstrom, R. W., Pilewskie, P., Russell, P. B., Redemann, J., Bond, T. C., Quinn, P. K., and Sierau, B.: Spectral absorption properties of atmospheric aerosols, Atmos. Chem. Phys., 7, 5937-5943, doi:10.5194/acp-7-5937-2007, 2007.

Bohren, C. and Clothiaux, E.: Fundamentals of Atmospheric Radiation: An Introduction with 400 Problems, Wiley-VCH Verlag GmbH \& Co. KGaA, Weinheim, 2006.

Bohren, C. and Huffman, D.: Absorption and Scattering of Light by Small Particles, Wiley, New York, 1983. 
Bond, T.: Spectral dependence of visible light absorption by carbonaceous particles emitted from coal combustion, Geophys. Res. Lett., 28, 4075-4078, 2001.

Bond, T. and Bergstrom, R.: Light absorption by carbonaceous particles: an investigative review, Aerosol Sci. Tech., 40, 27-67, 2006.

Bond, T., Doherty, S., Fahey, D., Forster, P., Berntsen, T., DeAngelo, B., Flanner, M., Ghan, S., Kärcher, B., Koch, D., Kinne, S., Kondo, Y., Quinn, P., Sarofim, M., Schultz, M., Schulz, M., Venkataraman, C., Zhang, H., Zhang, S., Bellouin, N., Guttikunda, S., Hopke, P., Jacobson, M., Kaiser, J., Klimont, Z., Lohmann, U., Schwarz, J., Shindell, D., Storelvmo, T., Warren, S., and Zender, C.: Bounding the role of black carbon in the climate system: a scientific assessment, J. Geophys. Res., 118, 1-173, doi:10.1002/jgrd.50171, 2013.

Cazorla, A., Bahadur, R., Suski, K. J., Cahill, J. F., Chand, D., Schmid, B., Ramanathan, V., and Prather, K. A.: Relating aerosol absorption due to soot, organic carbon, and dust to emission sources determined from in-situ chemical measurements, Atmos. Chem. Phys., 13, 9337-9350, doi:10.5194/acp-13-9337-2013, 2013.

Chakrabarty, R., Moosmüller, H., Garro, M., Arnott, W., Walker, J., Susott, R., Babbitt, R., Wold, C., Lincoln, E., and Hao, W.: Emissions from the laboratory combustion of wildland fuels: particle morphology and size, J. Geophys. Res., 111, D07204, doi:10.1029/2005JD006659, 2006.

Chakrabarty, R., Moosmüller, H., Arnott, W., Garro, M., Slowik, J., Cross, E., Han, J.-H., Davidovits, P., Onasch, T., and Worsnop, D.: Light scattering and absorption by fractal-like carbonaceous chain aggregates: comparison of theories and experiment, Appl. Optics, 46, 6990-7006, 2007.

Chakrabarty, R. K., Moosmüller, H., Chen, L.-W. A., Lewis, K., Arnott, W. P., Mazzoleni, C., Dubey, M. K., Wold, C. E., Hao, W. M., and Kreidenweis, S. M.: Brown carbon in tar balls from smoldering biomass combustion, Atmos. Chem. Phys., 10, 6363 6370, doi:10.5194/acp-10-6363-2010, 2010.

Chakrabarty, R., Arnold, I., Francisco, D., Hatchett, B., Hosseinpour, F., Loria, M., and Pokharel, A.: Black and brown carbon fractal aggregates from combustion of two fuels widely used in Asian rituals, J. Quant. Spectrosc. Ra., 122, 25-30, 2013.

Chen, C. and Cahan, B.: Visible and ultraviolet optical properties of single-crystal and polycrystalline hematite measured by spectroscopic ellipsometry, J. Opt. Soc. Am., 71, 932-934, 1981.

Chen, Y. and Bond, T. C.: Light absorption by organic carbon from wood combustion, Atmos. Chem. Phys., 10, 1773-1787, doi:10.5194/acp-10-1773-2010, 2010.

Chow, J., Watson, J., Doriaswamy, P., Chen, L.-W., Sodeman, D., Lowenthal, D., Park, K., Arnott, W., and Motallebi, N.: Aerosol light absorption, black carbon, and elemental carbon at the Fresno Supersite, California, Atmos. Res., 93, 874-887, 2009.

Chung, C., Lee, K., and Müller, D.: Effect of internal mixture on black carbon radiative forcing, Tellus B, 64, 10925, doi:10.3402/tellusb.v64i0.10925, 2012a.

Chung, C., Ramanathan, V., and Decremer, D.: Observationally constrained estimates of carbonaceous aerosol radiative forcing, P. Natl. Acad. Sci. USA, 109, 11624-11629, 2012 b.

Clarke, A., Shinozuka, Y., Kapustin, V., Howell, S., Huebert, B., Doherty, S., Anderson, T., Covert, D., Anderson, J., Hua, X., II, K. M., McNaughton, C., Carmichael, G., and Weber, R.: Size distributions and mixtures of dust and black carbon aerosol in Asian outflow: physiochemistry and optical properties, J. Geophys. Res., 109, D15S09, doi:10.1029/2003JD004378, 2004.

Clarke, A., McNaughton, C., Kapustin, V., Shinozuka, Y., Howell, S., Dibb, J., Zhou, J., Anderson, B., Brekhovskikh, V., Turner, H., and Pinkerton, M.: Biomass burning and pollution aerosol over North America: organic components and their influence on spectral optical properties and humidification response, J. Geophys. Res., 112, D12S18, doi:10.1029/2006JD007777, 2007.

Dinar, E., Abo Riziq, A., Spindler, C., Erlick, C., Kiss, G., and Rudich, Y.: The complex refractive index of atmospheric and model humic-like substances (HULIS) retreived by a cavity ring down aerosol spectrometer (CRD-AS), Faraday Discuss., 137, 279-295, 2008.

Dubovik, O. and King, M.: A flexible inversion algorithm for retrieval of aerosol optical properties from sun and sky radiance measurements, J. Geophys. Res., 105, 20673-20696, 2000.

Dubovik, O., Smirnov, A., Holben, B., King, M., Kaufman, Y., Eck, T., and Slutsker, I.: Accuracy assessments of aerosol optical properties retrieved from Aerosol Robotic Network (AERONET) sun and sky radiance measurements, J. Geophys. Res., 105, 9791-9806, 2000.

Dubovik, O., Holben, B., Eck, T., Smirnov, A., Kaufman, Y., King, M., Tanre, D., and Slutsker, I.: Variability of absorption and optical properties of key aerosol types observed in worldwide locations, J. Atmos. Sci., 59, 590-608, 2002a.

Dubovik, O., Holben, B., Lapyonok, T., Sinyuk, A., Mishchenko, M., Yang, P., and Slutsker, I.: Non-spherical aerosol retrieval method employing light scattering by spheroids, Geophys. Res. Lett., 29, 1415, doi:10.1029/2001GL014506, 2002b.

Dubovik, O., Sinyuk, A., Lapyonok, T., Holben, B., Mishchenko, M., Yang, P., Eck, T., Volten, H., Munoz, O., Veihelmann, B., van der Zande, W., Leon, J.-F., Sorokin, M., and Slutsker, I.: Application of spheroid models to account for aerosol particle nonsphericity in remote sensing of desert dust, J. Geophys. Res., 111, D11208, doi:10.1029/2005JD006619, 2006.

Eck, T., Holben, B. N., Reid, J., Dubovik, O., Smirnov, A., O’Neill, N., Slutsker, I., and Kinne, S.: Wavelength dependence of the optical depth of biomass burning, urban, and desert dust aerosols, J. Geophys. Res., 104, 31333-31349, 1999.

Eck, T., Holben, B., Sinyuk, A., Pinker, R., Goloub, P., Chen, H., Chatenet, B., Li, Z., Singh, R., Tripathi, S., Reid, J., Giles, D., Dubovik, O., O'Neill, N., Smirnov, A., Wang, P., and Xia, X.: Climatological aspects of the optical properties of fine/coarse mode aerosol mixtures, J. Geophys. Res., 115, D19205, doi:10.1029/2010JD014002, 2010.

Farias, T. L., Köylü, U. O., and Carvalho, M.: Range of validity of the Rayleigh-Debye-Gans theory for optics of fractal aggregates, Appl. Optics, 35, 6560-6567, 1996.

Flowers, B. A., Dubey, M. K., Mazzoleni, C., Stone, E. A., Schauer, J. J., Kim, S.-W., and Yoon, S. C.: Optical-chemicalmicrophysical relationships and closure studies for mixed carbonaceous aerosols observed at Jeju Island; 3-laser photoacoustic spectrometer, particle sizing, and filter analysis, Atmos. Chem. Phys., 10, 10387-10398, doi:10.5194/acp-10-10387-2010, 2010. 
Formenti, P., Rajot, J., Desboeufs, K., Caquineau, S., Chevaillier, S., Nava, S., Gaudichet, A., Journet, E., Triquet, S., Alfaro, S., Chiari, M., Haywood, J., Coe, H., and Highwood, E.: Regional variability of the composition of mineral dust from western Africa: results from the AMMA SOP0/DABEX and DODO field campaigns, J. Geophys. Res., 113, D00C13, doi:10.1029/2008JD009903, 2008.

Formenti, P., Caquineau, S., Chevaillier, S., Klaver, A., Desboeufs, K., Rajot, J. L., Belin, S., and Briois, V.: Dominance of goethite over hematite in iron oxides of mineral dust from Western Africa: quantitative partitioning by X-ray absorption spectroscopy, J. Geophys. Res., 119, 12740-12754, doi:10.1002/2014JD021668, 2014.

Fuller, K.: Scattering and absorption cross sections of compounded spheres: II. Calculations for external aggregation, J. Opt. Soc. Am. A, 12, 881-892, 1995.

Fuller, K., Malm, W., and Kreidenweis, S.: Effects of mixing on extinction by carbonaceous particles, J. Geophys. Res., 104, 15941-15954, 1999.

Ganguly, D., Jayaraman, A., Gadhavi, H., and Rajesh, T.: Features in wavelength dependence of aerosol absorption observed over central India, Geophys. Res. Lett., 32, L13821, doi:10.1029/2005GL023023, 2005.

Giles, D., Holben, B., Tripathi, S., Eck, T., Newcomb, W., Slutsker, I., Dickerson, R., Thomspon, A., Mattoo, S., Wang, S.H., Singh, R., Sinyuk, A., and Schafer, J.: Aerosol properties over the Indo-Gangetic Plain: a mesoscale perspective from the TIGERZ experiment, J. Geophys. Res., 116, D18203, doi:10.1029/2011JD015809, 2011.

Giles, D., Holben, B., Eck, T., Sinyuk, A., Smirnov, A., Slutsker, I., Dickerson, R., Thomspon, A., and Schafer, J.: An analysis of AERONET aerosol absorption properties and classifications representative of aerosol source regions, J. Geophys. Res., 117, D17203, doi:10.1029/2012JD018127, 2012.

Gillespie, J. and Lindberg, J.: Ultraviolet and visible imaginary refractive index of strongly absorbing atmospheric particulate matter, Appl. Optics, 31, 2112-2115, 1992.

Gyawali, M., Arnott, W. P., Lewis, K., and Moosmüller, H.: In situ aerosol optics in Reno, NV, USA during and after the summer 2008 California wildfires and the influence of absorbing and non-absorbing organic coatings on spectral light absorption, Atmos. Chem. Phys., 9, 8007-8015, doi:10.5194/acp-9-8007-2009, 2009.

Hand, V., Capes, G., Vaughan, D., Formenti, P., Haywood, J., and Coe, H.: Evidence of internal mixing of African dust and biomass burning particles by individual particle analysis using electron beam techniques, J. Geophys. Res., 115, D13301, doi:10.1029/2009JD012938, 2010.

Hoffer, A., Gelencsér, A., Guyon, P., Kiss, G., Schmid, O., Frank, G. P., Artaxo, P., and Andreae, M. O.: Optical properties of humic-like substances (HULIS) in biomass-burning aerosols, Atmos. Chem. Phys., 6, 3563-3570, doi:10.5194/acp-6-3563-2006, 2006.

Holben, B., Eck, T., Slutsker, I., Tanre, D., Buis, J., Setzer, A., Vermote, E., Reagan, J., Kaufman, Y., Nakajima, T., Lavenu, F., Jankowiak, I., and Smirnov, A.: AERONET - a federated instrument network and data archive for aerosol characterization, Remote Sens. Environ., 66, 1-16, 1998.
Holben, B., Tanre, D., Smirnov, A., Eck, T., Slutsker, I., Abuhassan, N., Newcomb, W., Schafer, J., Chatenet, B., Lavenu, F., Kaufman, Y., Castle, J. V., Setzer, A., Markham, B., Clark, D., Frouin, R., Halthore, R., Karneli, A., O'Neill, N., Pietras, C., Pinker, R., Voss, K., and Zibordi, G.: An emerging ground-based aerosol climatology: aerosol optical depth from AERONET, J. Geophys. Res., 106, 12067-12097, 2001.

Jacobson, M.: Isolating nitrated and aromatic aerosols and nitrated aromatic gases as sources of ultraviolet light absorption, J. Geophys. Res., 106, 3527-3542, 1999.

Jäger, C., Mutschke, H., and Henning, T.: Optical properties of carbonaceous dust analogues, Astron. Astrophys., 332, 291-299, 1998.

Kanakidou, M., Seinfeld, J. H., Pandis, S. N., Barnes, I., Dentener, F. J., Facchini, M. C., Van Dingenen, R., Ervens, B., Nenes, A., Nielsen, C. J., Swietlicki, E., Putaud, J. P., Balkanski, Y., Fuzzi, S., Horth, J., Moortgat, G. K., Winterhalter, R., Myhre, C. E. L., Tsigaridis, K., Vignati, E., Stephanou, E. G., and Wilson, J.: Organic aerosol and global climate modelling: a review, Atmos. Chem. Phys., 5, 1053-1123, doi:10.5194/acp-5-1053-2005, 2005.

Kandler, K. and Schütz, L.: Climatology of the average watersoluble volume fraction of atmospheric aerosol, Atmos. Res., 83, 77-92, 2007.

Kandler, K., Schütz, L., Deutscher, C., Ebert, M., Hofmann, H., Jäckel, S., Jaenicke, R., Knippertz, P., Lieke, K., Massling, A., Petzold, A., Schladitz, A., Weinzierl, B., Wiedensohler, A., Zorn, S., and Weinbruch, S.: Size distribution, mass concentration, chemical and mineralogical composition and derived optical parameters of the boundary layer aerosol at Tinfou, Morocco, during SAMUM 2006, Tellus B, 61, 32-50, 2009.

Kirchstetter, T., Novakov, T., and Hobbs, P.: Evidence that spectral dependence of light absorption by aerosols is affected by organic carbon, J. Geophys. Res., 109, D21208, doi:10.1029/2004JD004999, 2004.

Klaver, A., Formenti, P., Caquineau, S., Chevaillier, S., Ausset, P., Calzolai, G., Osborne, S., Johnson, B., Harrison, M., and Dubovik, O.: Physico-chemical and optical properties of Sahelian and Saharan mineral dust: in situ measurements during the GERBILS campaign, Q. J. Roy. Meteorol. Soc., 137, 1193-1210, 2011.

Kondo, Y., Sahu, L., Moteki, N., Khan, F., Takegawa, N., Liu, X., Koike, M., and Miyakawa, T.: Consistency and traceability of black carbon measurements made by laser-induced incandescence, thermal-optical transmittance, and filter-based photoabsorption techniques, Aerosol Sci. Tech., 45, 295-312, 2011.

Lack, D. A. and Cappa, C. D.: Impact of brown and clear carbon on light absorption enhancement, single scatter albedo and absorption wavelength dependence of black carbon, Atmos. Chem. Phys., 10, 4207-4220, doi:10.5194/acp-10-4207-2010, 2010.

Lack, D. A. and Langridge, J. M.: On the attribution of black and brown carbon light absorption using the Ångström exponent, Atmos. Chem. Phys., 13, 10535-10543, doi:10.5194/acp13-10535-2013, 2013.

Lack, D., Langridge, J., Bahreini, R., Cappa, C., Middlebrook, A., and Schwarz, J.: Brown carbon and internal mixing in biomass burning particles, P. Natl. Acad. Sci. USA, 109, 14802-14807, doi:10.1073/pnas.1206575109, 2012a. 
Lack, D., Richardson, M., Law, D., Langridge, J., Cappa, C., McLaughlin, R., and Murphy, D.: Aircraft instrument for comprehensive characterization of aerosol optical properties, Part 2: Black and brown carbon absorption and absorption enhancement measured with photo acoustic spectroscopy, Aerosol Sci. Tech., 46, 555-568, 2012b.

Lafon, S., Rajot, J.-L., Alfaro, S., and Gaudichet, A.: Quantification of iron oxides in desert aerosol, Atmos. Environ., 38, 1211-1218, 2004.

Lafon, S., Sokolik, I., Rajot, J., Caquineau, S., and Gaudichet, A.: Characterization of iron oxides in mineral dust aerosols: implications for light absorption, J. Geophys. Res., 111, D21207, doi:10.1029/2005JD007016, 2006.

Lewis, K., Arnott, W., Moosmüller, H., and Wold, C.: Strong spectral variation of biomass smoke light absorption and single scattering albedo observed with a novel dual-wavelength photoacoustic instrument, J. Geophys. Res., 113, D116203, doi:10.1029/2007JD009699, 2008.

Li, J., Anderson, J. R., and Buseck, P.: TEM study of aerosol particles from clean and polluted marine boundary layers over the North Atlantic, J. Geophys. Res., 108, 4189, doi:10.1029/2002JD002106, 2003a.

Li, J., Posfai, M., Hobbs, P., and Buseck, P.: Individual aerosol particles from biomass burning in southern Africa: 2. Compositions and aging of inorganic particles, J. Geophys. Res., 108, 8484, doi:10.1029/2002JD002310, 2003b.

Li, J., Carlson, B., and Lacis, A.: Using single-scattering albedo spectral curvature to characterize East Asian aerosol mixtures, J. Geophys. Res., 120, doi:10.1002/2014JD022433, 2015.

Linke, C., Möhler, O., Veres, A., Mohácsi, Á., Bozóki, Z., Szabó, G., and Schnaiter, M.: Optical properties and mineralogical composition of different Saharan mineral dust samples: a laboratory study, Atmos. Chem. Phys., 6, 3315-3323, doi:10.5194/acp-63315-2006, 2006.

Liu, Z., Omar, A., Vaughan, M., Hair, J., Kittaka, C., Hu, Y., Powell, K., Trepte, C., Winker, D., Hostetler, C., Ferrare, R., and Pierce, R.: CALIPSO lidar observations of the optical properties of Saharan dust: a case study of long-range transport, J. Geophys. Res., 113, D07207, doi:10.1029/2007JD008878, 2008.

Mallet, M., Roger, J., Despiau, S., Dubovik, O., and Putaud, J.: Microphysical and optical properties of aerosol particles in urban zone during ESCOMPTE, Atmos. Res., 69, 73-97, 2003.

Martins, J., Artaxo, P., Liousse, C., Reid, J., Hobbs, P., and Kaufman, Y.: Effects of black carbon content, particle size, and mixing on light absorption by aerosols from biomass burning in Brazil, J. Geophys. Res., 103, 32041-32050, 1998.

Moffet, R. and Prather, K. A.: In-situ measurements of the mixing state and optical properties of soot with implications for radiative forcing estimates, P. Natl. Acad. Sci. USA, 106, 11872-11877, 2009.

Moosmüller, H., Chakrabarty, R., and Arnott, W.: Aerosol light absorption and its measurement: a review, J. Quant. Spectrosc. Ra., 110, 844-878, 2009.

Moosmüller, H., Chakrabarty, R. K., Ehlers, K. M., and Arnott, W. P.: Absorption Ångström coefficient, brown carbon, and aerosols: basic concepts, bulk matter, and spherical particles, Atmos. Chem. Phys., 11, 1217-1225, doi:10.5194/acp-11-12172011, 2011.
Moteki, N., Kondo, Y., Miyazaki, Y., Takegawa, N., Kurata, G., Shirai, T., Blake, D., Miyakawa, T., and Koike, M.: Evolution of mixing state of black carbon particles: Aircraft measurements over the western Pacific in March 2004, Geophys. Res. Lett., 34, L11803, doi:10.1029/2006GL028943, 2007.

Moteki, N., Kondo, Y., and Nakamura, S.: Method to measure refractive indices of small nonspherical particles: Application to black carbon particles, J. Aerosol Sci., 41, 513-521, 2010.

Mulholland, G. and Mountain, R.: Coupled dipole calculation of extinction coefficient and polarization ratio for smoke agglomerates, Combust. Flame, 119, 56-68, 1999.

Mulholland, G., Bohren, C., and Fuller, K.: Light scattering by agglomerates: Coupled electric and magnetic dipole method, Langmuir, 10, 2533-2546, 1994.

Pósfai, M., Simonics, R., Li, J., Hobbs, P., and Buseck, P.: Individual aerosol particles from biomass burning in southern Africa: 1 . Compositions and size distributions of carbonaceous particles, J. Geophys. Res., 108, 8483, doi:10.1029/2002JD002291, 2003.

Roden, C., Bond, T., Conway, S., Benjamin, A., and Pinel, O.: Emission factors and real-time optical properties of particles emitted from traditional wood burning cookstoves, Environ. Sci. Technol., 40, 6750-6757, 2006.

Rosen, H., Hansen, A., Gundel, L., and Novakov, T.: Identification of the optically absorbing component in urban aerosols, Appl. Optics, 17, 3859-3861, 1978.

Russell, P. B., Bergstrom, R. W., Shinozuka, Y., Clarke, A. D., DeCarlo, P. F., Jimenez, J. L., Livingston, J. M., Redemann, J., Dubovik, O., and Strawa, A.: Absorption Angstrom Exponent in AERONET and related data as an indicator of aerosol composition, Atmos. Chem. Phys., 10, 1155-1169, doi:10.5194/acp-101155-2010, 2010.

Russell, P., Kacenelenbogen, M., Livingston, J., Hasekamp, O., Burton, S., Schuster, G., Johnson, M., Knobelspiesse, K., Redemann, J., Ramachandran, S., and Holben, B.: A multiparameter aerosol classification method and its application to retrievals from spaceborne polarimetry, J. Geophys. Res., 119, doi:10.1002/2013JD021411, 2014.

Sato, M., Hansen, J., Koch, D., Lacis, A., Ruedy, R., Dubovik, O., Holben, B., Chin, M., and Novakov, T.: Global atmospheric black carbon inferred from AERONET, P. Natl. Acad. Sci. USA, 100, 6319-6324, 2003.

Schnaiter, M., Horvath, H., Möhler, O., Naumann, K.-H., Saathoff, H., and Schöck, O.: UV-VIS-NIR spectral optical properties of soot and soot-containing aerosols, J. Aerosol Sci., 34, 1421-1444, 2003.

Schnaiter, M., Linke, C., Möhler, O., Naumann, K.-H., Saathoff, H., Wagner, R., and Schurath, U.: Absorption amplification of black carbon internally mixed with secondary organic aerosol, J. Geophys. Res., 110, D19204, doi:10.1029/2005JD006046, 2005.

Schnaiter, M., Gimmler, M., Llamas, I., Linke, C., Jäger, C., and Mutschke, H.: Strong spectral dependence of light absorption by organic carbon particles formed by propane combustion, Atmos. Chem. Phys., 6, 2981-2990, doi:10.5194/acp-6-2981-2006, 2006.

Schuster, G. L., Dubovik, O., Holben, B. N., and Clothiaux, E. E.: Inferring black carbon content and specific absorption from Aerosol Robotic Network (AERONET) aerosol retrievals, J. Geophys. Res., 110, D10S17, doi:10.1029/2004JD004548, 2005. 
Schuster, G., Dubovik, O., and Holben, B.: Ångström exponent and bimodal aerosol size distributions, J. Geophys. Res., 111, D07207, doi:10.1029/2005JD006328, 2006.

Schuster, G. L., Vaughan, M., MacDonnell, D., Su, W., Winker, D., Dubovik, O., Lapyonok, T., and Trepte, C.: Comparison of CALIPSO aerosol optical depth retrievals to AERONET measurements, and a climatology for the lidar ratio of dust, Atmos. Chem. Phys., 12, 7431-7452, doi:10.5194/acp-12-7431-2012, 2012.

Schuster, G. L., Dubovik, O., and Arola, A.: Remote sensing of soot carbon - Part 1: Distinguishing different absorbing aerosol species, Atmos. Chem. Phys., 16, 1565-1585, doi:10.5194/acp16-1565-2016, 2016.

Schwarz, J., Gao, R., Spackman, J., Watts, L., Thomson, D., Fahey, D., Ryerson, T., Peischl, J., Holloway, J., Trainer, M., Frost, G., Baynard, T., Lack, D., de Gouw, J., Warneke, C., and Negro, L. D.: Measurement of the mixing state, mass, and optical size of individual black carbon particles in urban and biomass burning emissions, Geophys. Res. Lett., 35, L13810, doi:10.1029/2008GL033968, 2008a.

Schwarz, J., Spackman, J., Fahey, D., Gao, R., Lohmann, U., Stier, P., Watts, L., Thomson, D., Lack, D., Pfister, L., Mahoney, M., Baumgardner, D., Wilson, J., and Reeves, J.: Coatings and their enhancement of black carbon light absorption in the tropical atmosphere, J. Geophys. Res., 113, D03203, doi:10.1029/2007JD009042, 2008b.

Schwarz, J., Spackman, J., Gao, R., Watts, L., Stier, P., Schulz, M., Davis, S., Wofsy, S., and Fahey, D.: Globalscale black carbon profiles observed in the remote atmosphere and compared to models, Geophys. Res. Lett., 37, L18812, doi:10.1029/2010GL044372, 2010.

Shi, Z., Krom, M., Jickells, T., Bonneville, S., Carslaw, K., Mihalopoulos, N., Baker, A., and Benning, L.: Impacts on iron solubility in the mineral dust by processes in the source region and the atmosphere: a review, Aeolian Res., 5, 21-42, 2012.
Smirnov, A., Holben, B., Eck, T., Dubovik, O., and Slutsker, I.: Cloud screening and quality control algorithms for the AERONET database, Remote Sens. Environ., 73, 337-349, 2000.

Sorensen, C.: Light scattering by fractal aggregates: a review, Aerosol Sci. Tech., 35, 648-687, 2001.

Sun, H., Biedermann, L., and Bond, T.: Color of brown carbon: a model for ultraviolet and visible light absorption by organic carbon aerosol, Geophys. Res. Lett., 34, L17813, doi:10.1029/2007GL029797, 2007.

Utry, N., Ajtai, T., Filep, A., Pintér, M., Török, Z., and G. Szabó, Z. B.: Correlations between absorption Angström exponent (AAE) of wintertime ambient urban aerosol and its physical and chemical properties, Atmos. Environ., 91, 52-59, 2014.

Wentzel, M., Gorzawski, H., Naumann, K.-H., Saathoff, H., and Weinbruch, S.: Transmission electron microscopical and aerosol dynamical chacterization of soot aerosols, J. Aerosol Sci., 34, 1347-1370, 2003.

Wu, Y., Gu, X., Cheng, T., Xie, D., Yu, T., Chen, H., and Guo, J.: The single scattering properties of the aerosol particles as aggregated spheres, J. Quant. Spectrosc. Ra., 113, 1454-1466, 2012.

Xu, Y., Bahadur, R., Zhao, C., and Leung, L.: Estimating the radiative forcing of carbonaceous aerosols over California based on satellite and ground observations, J. Geophys. Res., 118, 1114811160, doi:10.1002/jgrd.50835, 2013.

Yang, M., Howell, S. G., Zhuang, J., and Huebert, B. J.: Attribution of aerosol light absorption to black carbon, brown carbon, and dust in China - interpretations of atmospheric measurements during EAST-AIRE, Atmos. Chem. Phys., 9, 2035-2050, doi:10.5194/acp-9-2035-2009, 2009. 